\title{
REVIEW \\ Redox regulation in tumor cell epithelial-mesenchymal transition: molecular basis and therapeutic strategy
}

\author{
Jingwen Jiang ${ }^{1,4}$, Kui Wang ${ }^{1,4}$, Yan Chen ${ }^{1,4}$, Haining Chen ${ }^{2}$, Edouard C Nice ${ }^{3}$ and Canhua Huang ${ }^{1}$
}

Epithelial-mesenchymal transition (EMT) is recognized as a driving force of cancer cell metastasis and drug resistance, two leading causes of cancer recurrence and cancer-related death. It is, therefore, logical in cancer therapy to target the EMT switch to prevent such cancer metastasis and recurrence. Previous reports have indicated that growth factors (such as epidermal growth factor and fibroblast growth factor) and cytokines (such as the transforming growth factor beta (TGF- $\beta$ ) family) are major stimulators of EMT. However, the mechanisms underlying EMT initiation and progression remain unclear. Recently, emerging evidence has suggested that reactive oxygen species (ROS), important cellular secondary messengers involved in diverse biological events in cancer cells, play essential roles in the EMT process in cancer cells by regulating extracellular matrix (ECM) remodeling, cytoskeleton remodeling, cell-cell junctions, and cell mobility. Thus, targeting EMT by manipulating the intracellular redox status may hold promise for cancer therapy. Herein, we will address recent advances in redox biology involved in the EMT process in cancer cells, which will contribute to the development of novel therapeutic strategies by targeting redox-regulated EMT for cancer treatment.

Signal Transduction and Targeted Therapy (2017) 2, e17036; doi:10.1038/sigtrans.2017.36; published online 18 August 2017

\section{INTRODUCTION}

In the early 1980s, Elizabeth Hay observed a phenotypic transition of epithelial cells to acquire mesenchymal characteristics. ${ }^{1}$ This differentiation process is now widely known as epithelialmesenchymal transition (EMT), which is involved in embryonic development, wound healing and cancer progression. ${ }^{2-5}$ Epithelial and mesenchymal cells can be discriminated by distinct morphologic features: epithelial cells are laterally conjoined to form layers or polarized sheets, whereas mesenchymal cells rarely exhibit conjunctions with adjacent cells. ${ }^{6}$ Epithelial cells can be recognized by so-called epithelial markers, including claudins, E-cadherin, Crumbs3 and PALS1, all of which are critical for maintaining cell-cell junctions and cell polarity. By contrast, mesenchymal cells are characterized by key migration-promoting genes, such as $\mathrm{N}$-cadherin, vimentin, a-smooth muscle actin (a-SMA) and fibroblast activation protein (FAP). ${ }^{7}$ The major changes of epithelial cells undergoing EMT include the following: (1) diminished cellular conjunctions (including adherens junctions, tight junctions, gap junctions and desmosomes); (2) decreased focal adhesion; (3) downregulated epithelial markers and upregulated mesenchymal markers; (4) increased cell mobility; (5) remodeled cytoskeleton; (6) and degraded ECM. ${ }^{8,9}$ Several transcription factors, such as Snail, Slug, Twist, ZEB1 and ZEB2, are responsible for repressing epithelial markers and upregulating genes associated with the mesenchymal phenotype. ${ }^{10,11}$ These transcription factors are tightly regulated by the nuclear factor- $\mathrm{\kappa B}$ (NF-KB), hypoxia-inducible factor 1 (HIF-1) and transforming growth factor beta (TGF- $\beta$ ) signaling pathways. In addition, the transcription factor forkhead box class $\mathrm{O}$ (FoxO) can modulate ECM turnover and cell mobility by promoting the expression of matrix metalloproteinases (MMPs). ${ }^{12}$ Importantly, the subcellular localization of $\beta$-catenin is also critical for regulating the EMT process. On the cytomembrane, $\beta$-catenin tightly interacts with E-cadherin to maintain cell adhesion. When Wnt signaling is activated, $\beta$-catenin dissociates from E-cadherin, translocates to the nucleus and binds with TCF/LEF to activate the transcription of Snail, Twist and MMP-7. ${ }^{13}$ Although various transcription factors and modulators of EMT have been extensively studied, the precise mechanisms underlying EMT progression remain unclear. Importantly, a number of key EMT regulators were recently found to be redox-sensitive, enabling the elucidation of the molecular basis underlying the EMT process from a redox perspective. ${ }^{14-16}$

ROS are defined as oxygen-containing species that have highly reactive properties, and include free radicals such as hydroxyl free radicals $\left(\mathrm{HO}^{\circ}\right)$, superoxide $\left(\mathrm{O}_{2}^{--}\right)$and non-radical molecules such as hydrogen peroxide $\left(\mathrm{H}_{2} \mathrm{O}_{2}\right) .{ }^{17,18}$ ROS are important second messengers that regulate multifarious signaling pathways involved in cell proliferation, apoptosis, autophagy, migration, DNA damage, inflammation and drug resistance. ${ }^{19-21}$ Recently, the reversible and irreversible oxidative modifications of redoxsensitive proteins that possess free thiols (-SH) on cysteine residues, which are susceptible to ROS, have been found to play a crucial role in regulating signaling pathways. Several patterns of oxidative modifications have been reported, including sulfenylation $(-\mathrm{SOH})$, sulfinylation $\left(-\mathrm{SO}_{2} \mathrm{H}\right)$, sulfonylation $\left(-\mathrm{SO}_{3} \mathrm{H}\right)$, S-glutathionylation (PrS-SG) and disulfide bonds (intramolecular, intermolecular and mixed types). ${ }^{22}$ Through these redox modifications, ROS can alter the biological functions of redox-sensitive proteins involved in ECM remodeling (for example, integrin, $\mathrm{Hu}$ antigen R), cytoskeleton remodeling (for example, actin, cofilin),

\footnotetext{
${ }^{1}$ State Key Laboratory of Biotherapy and Cancer Center, West China Hospital, Sichuan University, and Collaborative Innovation Center for Biotherapy, Chengdu, China;

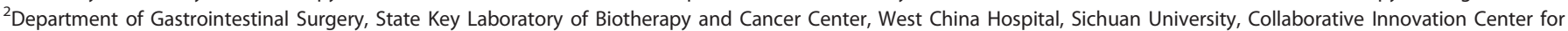
Biotherapy, Chengdu, China and ${ }^{3}$ Department of Biochemistry and Molecular Biology, Monash University, Clayton, Victoria, Australia.

Correspondence: C Huang (hcanhua@hotmail.com)

${ }^{4}$ These authors contributed equally to this work.

Received 31 December 2016; revised 25 April 2017; accepted 25 April 2017
} 
cell-cell junctions (for example, NF-KB, HIF-1a, TGF- $\beta$ ) and cell mobility (for example, Src, FAK, PTEN), thereby regulating EMT initiation and cancer cell progression. ${ }^{9}$

In this review, we will highlight recent progress in understanding the molecular basis of redox-regulated EMT in cancer cells and discuss the opportunities and challenges for targeting redox-regulated EMT as a potential therapeutic strategy for cancer.

\section{REDOX REGULATION OF ECM REMODELING}

During EMT, ECM proteins undergo degradation to confer cells with invasive potential. ECM stabilization is closely correlated with the expression of MMPs. The urokinase plasminogen activator (uPA) pathway has been reported to participate in ECM turnover and could be regulated by ROS. Integrins are believed to be important transmembrane proteins that link intracellular signaling mediators and ECM proteins. When EMT is initiated, the original integrins will be downregulated, and other types of integrin will be expressed, leading to new interactions with different ECM components to promote cell invasion. ${ }^{23}$ Recent studies have suggested that ECM remodeling could be mediated by redox regulation. Some integrins function as redox sensors; thus, this information may reveal a new perspective for uncovering the mask of ECM remodeling and integrin arrangement.

\section{Integrin arrangement}

Integrins are cell surface adhesion molecules that link the ECM to the intracellular actin cytoskeleton. They are heterodimeric receptors consisting of 18 a-subunits and $8 \beta$-subunits, which can assemble into at least 20 different integrins. These integrins differentially act to regulate cellular processes by binding to selective extracellular substrates. ${ }^{24}$ The extracellular domain of integrins can bind ECM proteins such as fibronectin, laminin and collagen. This binding causes the integrins to undergo conformational changes, exposing their cytoplasmic tail, which leads to linkage with the actin cytoskeleton. ${ }^{25}$ Moreover, integrin engagement can activate Src and FAK, both of which are involved in coordinating the reorganization of the actin cytoskeleton. ${ }^{26}$ It has been confirmed that integrin $\alpha 7 \beta 1$ is a redox sensor that can be oxidized and activated by ROS (generated by NADPH oxidase 4, NOX4). Treatment with diphenylene iodonium chloride (DPI, an inhibitor of NOX) can rescue the attachment of rat aortic smooth muscle cells to laminin-111. ${ }^{27}$ Two sites on integrin a7 have been identified to be modulated by $\mathrm{H}_{2} \mathrm{O}_{2}$, one being located in the genu region and another in the calf 2 domain. Within the calf 2 domain, Cys862 can form different disulfide bridge-stabilized conformations by cross-linking with Cys916, Cys923, or Cys928. In the genu region, 2 cysteine residues (Cys604 and Cys610) can simultaneously undergo oxidized modifications by ROS, contributing to the conformational switch, finally leading to the activation of integrin $a 7 \beta 1$ and its binding with laminin-111 (Figure 1).

\section{The uPA pathway}

Urokinase plasminogen activator (UPA) is an extracellular serine protease that can be activated by binding to its specific receptor UPAR. Activated UPA mediates the cleavage of plasminogen to form plasmin, which is required for ECM degradation and MMP activation. High uPAR expression is associated with poor prognosis of patients with multiple types of cancer, suggesting a positive correlation between upregulated uPAR and tumor malignancy. ${ }^{28}$ It has been reported that ROS can induce the transcription of both UPA and UPAR by regulating activator protein-1 (AP-1) and NF-K $\mathrm{B}^{29}$ Moreover, the mRNA-stabilizing factor $\mathrm{Hu}$ antigen $\mathrm{R}$ (HuR), which binds to the instability-determining AU-rich elements (ARE) of UPA and UPAR, can also be regulated by $\mathrm{ROS}^{30} \mathrm{H}_{2} \mathrm{O}_{2}$ treatment promotes the phosphorylation of mitogen-activated protein

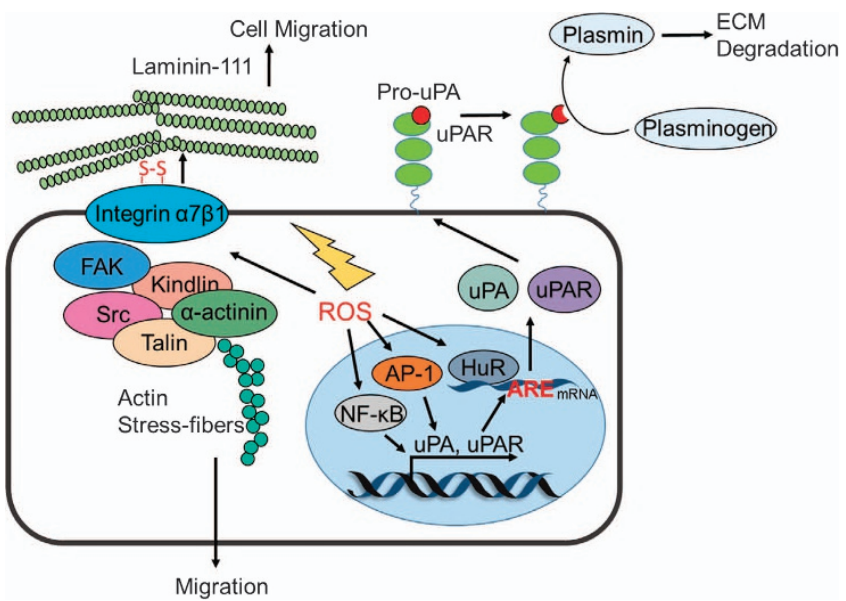

Figure 1. Redox regulation of ECM remodeling. Integrins can undergo oxidative modification by ROS during the initiation of EMT. Oxidized integrin $\alpha 7 \beta 1$ binds to laminin-111 and activates its downstream proteins, including FAK and Src. The uPA system is also tightly regulated by ROS. ROS promote the transcription of UPA and UPAR by activating the AP-1 and NF- $\kappa B$ signaling pathways. Moreover, ROS can stabilize UPA and UPAR mRNA by enhancing the binding of HuR with $A R E^{\mathrm{uPA}}$, leading to overexpression of $\mathrm{UPA}$ and $\mathrm{UPAR}$ and the subsequent activation of plasmin. ECM, extracellular matrix; EMT, epithelial-mesenchymal transition; FAK, focal adhesion kinase; UPA, urokinase plasminogen activator; ROS, reactive oxygen species; UPAR, urokinase plasminogen activator receptor; AP-1, activator protein-1; NF- $\mathrm{KB}$, nuclear factor- $\mathrm{\kappa} B$; $\mathrm{HuR}$, $\mathrm{Hu}$ antigen $\mathrm{R}$; $A R E, A U$-rich elements.

kinase-activated protein (MAPKAP) kinase 2 (MK2) and enhances the binding of HuR with ARE ${ }^{\mathrm{UPA}}$, thus increasing the expression of UPA and UPAR (Figure 1). The intrinsic links between HuR and oxidative stress were further strengthened by the finding that HuR silencing accounts for increased ROS levels in triple-negative breast cancer (TNBC). ${ }^{31}$ Excessive ROS caused by HuR knockdown led to the radiosensitization of tumor cells, providing a potential strategy for the treatment of advanced breast cancer. However, the actual mechanisms underlying how ROS mediates the binding of $\mathrm{HuR}$ and $A R E^{\mathrm{uPA}}$ requires further investigation.

\section{REDOX REGULATION OF CYTOSKELETON REMODELING}

Cytoskeleton remodeling is important for regulating cell elongation and contractility. ${ }^{32}$ Although cofilin and moesin have been reported to regulate dynamic actin reorganization, the mechanism underlying the subtle control of actin dynamics remains unclear. Recently, increasing evidence has suggested that ROS play important roles in the regulation of dynamic actin polymerization.

The cytoskeleton is composed of the microtubule network, intermediate filaments and the actin cytoskeleton, and it plays important roles in controlling cell shape. Specifically, actin cytoskeleton remodeling acts as a driving force for cell migration due to the dynamic alteration of cellular protrusions that occurs. ${ }^{33}$ The dynamic actin network is controlled by Rac, an upstream regulator of NOX, implying that ROS may be involved in actin cytoskeleton regulation. Recent studies have shown that Racmediated actin remodeling is attributed to increased $\mathrm{O}_{2}^{--}$levels. Deletion of $\mathrm{O}_{2}^{--}$using DPI or MnTMPyP reduced actin elongation and endothelial cell migration. ${ }^{34}$ Notably, actin can be directly oxidized by ROS. Cys374 in the C-terminal region of $\beta$-actin can be oxidized in both the G-actin (monomeric) and F-actin (polymerized) forms, with the oxidized form of actin slowing actin polymerization. ${ }^{35}$ Moreover, oxidized $\beta$-actin has been reported to promote actin depolymerization, partially due to decreased affinity with profilin. Another study found that $\beta$-actin could form 
mixed disulfides with glutathione. The reversion of actin glutathionylation (for example, by inhibiting 5-lipoxygenase) contributes to the inhibition of actinomyosin disassembly. ${ }^{36}$ ROS accumulation induced by Mical enzymes is also linked to the remodeling of $\mathrm{F}$-actin via oxidative modifications of cytoskeletal and nuclear actin. ${ }^{37,38}$ Thioredoxin (Trx) and SelR enzymes are now known to reverse the oxidative modification of actin. The Mical enzymes together with SelR reductases orchestrate the assembly and disassembly of actin filaments through a redox regulatory mechanism (Figure 2). ${ }^{39}$ Similar to actin, tubulin is another critical component of the cytoskeleton that can be modulated by oxidative stress. ${ }^{40}$ In the presence of $\mathrm{H}_{2} \mathrm{O}_{2}$ or $\mathrm{HOCl}$, tubulin can form tetramers by oxidative modification. ${ }^{41}$ In addition, treatment with paraquat, a ROS inducer, results in cytoskeletal injury by diminishing tubulin and microtubules. ${ }^{42}$ These studies indicate that oxidative stress monitors cytoskeleton remodeling via the redox regulation of both actin and tubulin.

Lamellipodia and filopodia are actin-rich membrane projections that act as sensory extensions of the cytoskeleton. Lamellipodia are flat protrusions that are distributed with highly branched actin filaments to form the leading edges of migrating cells. ${ }^{43}$ The actinbinding protein cofilin is a major regulator of actin reorganization and lamellipodia formation. Cofilin activation can be modulated by its phosphorylation status, which is controlled by Slingshot (SSH) and Slingshot-1L (SSH-1L). Notably, ROS can modulate the activity of $\mathrm{SSH}-1 \mathrm{~L}$ by mediating the association of $\mathrm{SSH}-1 \mathrm{~L}$ and its negative regulator $14-3-3 \zeta$. Once oxidized by ROS, $14-3-3 \zeta$ can reverse the inhibition of $\mathrm{SSH}-1 \mathrm{~L}$, ultimately leading to the formation of a cofilin-actin rod (Figure 2). ${ }^{44}$ Consistently, upon exposure to ROS, retrograde F-actin flow is dramatically potentiated in lamellipodium. ${ }^{45}$ The involvement of ROS in regulating actin reorganization was further substantiated by investigating the influence of oxidized actin on the actomyosin complex. Oxidized actin could promote the contractility of actomyosin by inducing the disassembly of actin and myosin, leading to the formation of stress fibers and the promotion of cell spreading. ROS elimination with GSH or overexpression of the $\beta$-actin C374A mutant dramatically inhibited the disassembly of actomyosin. ${ }^{46}$ Further investigations are required to clarify the interplay between ROS

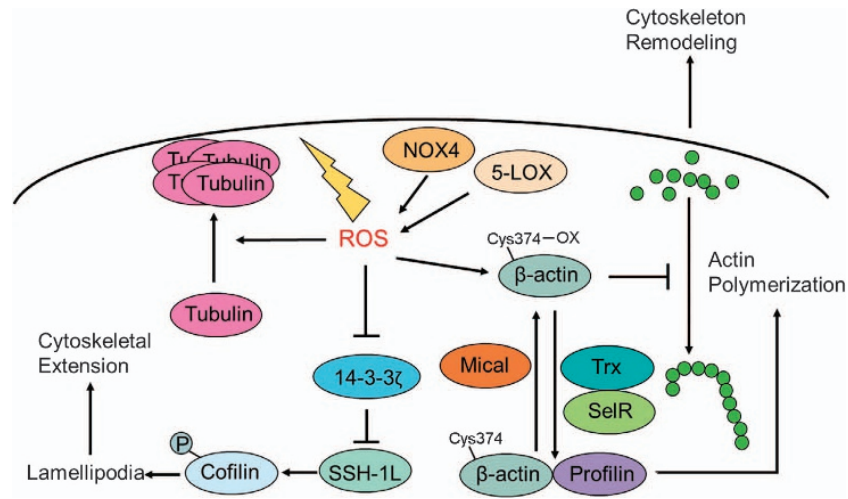

Figure 2. Redox regulation of cytoskeleton remodeling. Cys374 of $\beta$ actin can be oxidized in response to oxidative stress, leading to decreased actin polymerization and enhanced cytoskeleton remodeling. Mical promotes the oxidation of $\beta$-actin, whereas Trx and SelR mediate the reduction of $\beta$-actin. In addition, tubulin can also be regulated by ROS. ROS promote the formation of tubulin tetramers, leading to cytoskeletal injury. Moreover, ROS can also affect the formation of lamellipodia by inhibiting the activity of 14-3$3 \zeta$. Once oxidized, the inhibitory effect of $14-3-3 \zeta$ on $\mathrm{SSH}-1 \mathrm{~L}$ will be alleviated, ultimately leading to the formation of the cofilin-actin rod and lamellipodia. Trx, thioredoxin; ROS, reactive oxygen species; SSH-1L, Slingshot-1L; NOX4, NADPH oxidase 4; 5-LOX, 5-lipoxygenase. generation and actin cytoskeleton remodeling to understand in depth how EMT and cell migration occurs.

\section{REDOX REGULATION OF CELL-CELL JUNCTIONS}

Cell-cell junctions are essential for maintaining epithelial integrity. ${ }^{47}$ EMT initiation causes the diminishment of cell junctions and the deconstruction of epithelia-formed permeability barriers. Loss of tight junctions is commonly accompanied by decreased expression of occludin and claudin, whereas E-cadherin degradation is pivotal for the dissolution of adherens junctions. ${ }^{48,49}$ Moreover, during the destabilization of gap junctions, the expression of connexin is dramatically decreased, leading to the loss of cell-cell communication. These junction proteins are repressed during EMT by transcription factors such as Snail, Slug, Twist and ZEB. It is well-established that these key EMTinducing transcription factors are regulated by the convergence of signaling pathways, including the NF-KB, HIF- 1 and TGF- $\beta$ pathways. ${ }^{50-52}$ These signaling pathways modulate not only EMT-inducing transcription factors but also key regulators involved in cell mobility and cytoskeleton remodeling. Below, we will discuss the role of redox regulation in these signaling pathways and highlight the importance of ROS in EMT initiation.

\section{NF-KB}

The NF-KB transcription factor family consists of 5 members: p50, p52, p65 (RelA), RelB and c-Rel. All members have a Rel homology domain (RHD), which is required for dimerization and DNA binding. ${ }^{53,54}$ Normally, NF-KB is a hetero/homodimer that can be inactivated by inhibitors of kappa $B(I \kappa B)$ in the cytoplasm. In the presence of certain cellular stimuli, NF-KB signaling is activated by the IKB kinase (IKK) complex-mediated Ser32/36 phosphorylation of $\mathrm{IKB} .^{55}$ Activation of NF-KB signaling is strongly associated with the EMT process by promoting the expression of Twist1, Snail1, Slug and ZEB1/2, which contributes to the disruption of cell-cell junctions. ${ }^{56}$ Specifically, NF-KB activation also induces the transcription of vimentin and MMPs (such as MMP-2, MMP-9) to maintain the mesenchymal phenotype and promote tumor cell migration. Moreover, NF-KB is required for the stimulation of COP9 signalosome 2 (CSN2) to suppress the ubiquitination-mediated degradation of Snail, thereby resulting in cancer cell metastasis. ${ }^{3}$ Notably, it has been reported that oxidative stress plays a vital role in regulating NF-KB signaling (Figure 3 ). For instance, increased ROS levels can activate NF-KB signaling and induce EMT-related morphological changes, whereas administration of the antioxidant $\mathrm{N}$-acetylcysteine (NAC) or the NF-KB-specific inhibitor DHMEQ significantly reverses ROS-induced EMT. ${ }^{57-59}$ Furthermore, ROS confer pancreatic cancer cells with invasive ability by activating NF-KB signaling. Catalase treatment reverses EMT initiation, indicating that $\mathrm{H}_{2} \mathrm{O}_{2}$ may play an important role in NF-kBmediated EMT. ${ }^{60}$ In addition, TNFR (tumor necrosis factor receptor) activation induces ROS accumulation, leading to the phosphorylation and subsequent degradation of $1 \kappa B{ }^{61}$ In the cytoplasm, NF-KB essential modulator (NEMO, also known as IKKY) is activated by forming an intermolecular disulfide bond between Cys54 and Cys347 in response to oxidative stress. ${ }^{62}$ Even more perplexing, accumulating evidence suggests that ROS may inhibit NF-KB signaling. Notably, Cys62 of p50 can undergo glutathionylation in the nucleus, which inhibits its DNA-binding ability; however, this process can be reversed by Trx. Moreover, Kelch-like ECHassociated protein 1 (KEAP1) has been reported to inhibit NF-KB signaling via the $\mathrm{H}_{2} \mathrm{O}_{2}$-mediated degradation of IKK $3{ }^{63}$ These observations imply that ROS in diverse cellular compartments may lead to disparate consequences in redox-regulated NF-KB signaling. 


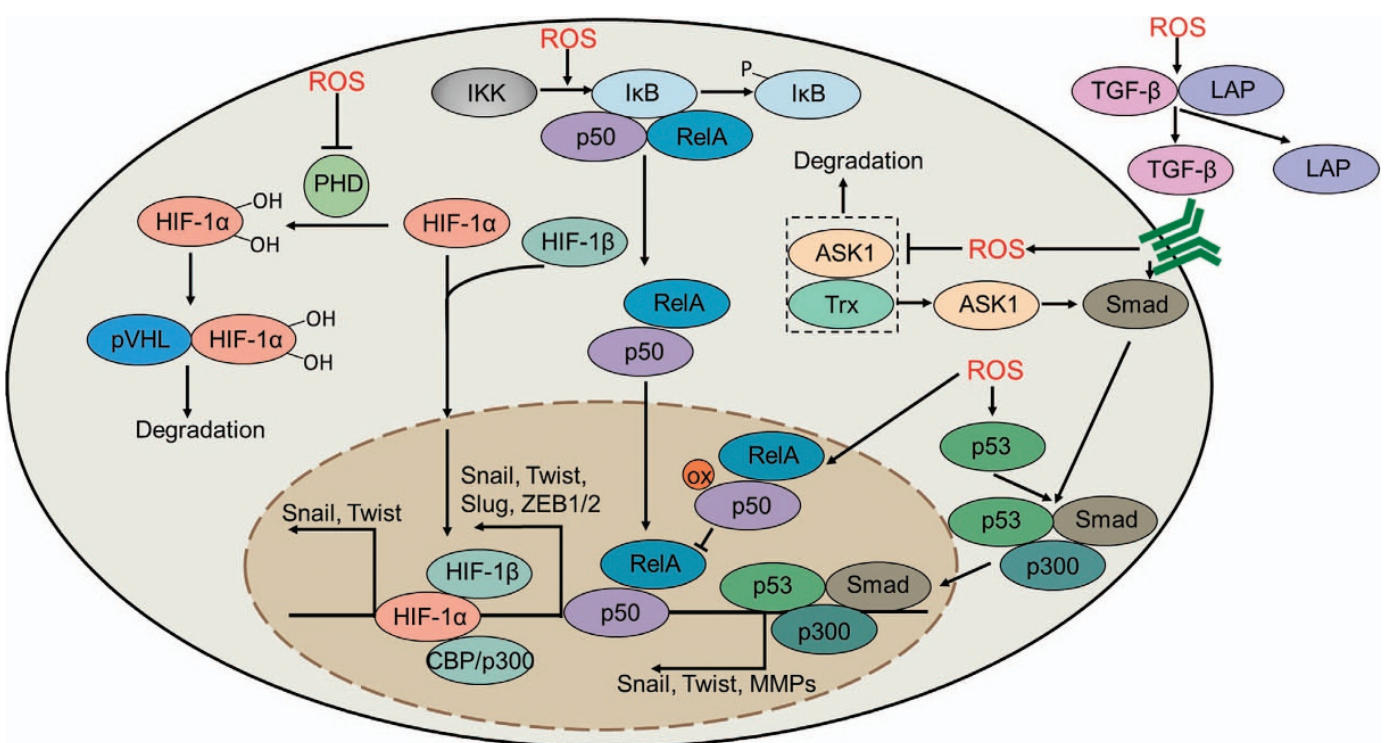

Figure 3. Redox regulation of cell-cell junctions. HIF-1 $\alpha$ can be hydroxylated by PHD and subsequently undergoes degradation by interacting with pVHL. ROS inhibit the activity of PHD to stabilize HIF-1 $\alpha$, thus inducing the transcription of Snail and Twist. Moreover, ROS promote the IKK-mediated degradation of $\mathrm{I} \mathrm{K}$ and induce the nuclear translocation of NF- $\kappa \mathrm{B}$, leading to the transcriptional activation of Snail, Slug, Twist and ZEB1/2. However, ROS also inhibit the NF-кB signaling pathway by oxidizing p50 in the nucleus. ROS can also activate the TGF- $\beta$ signaling pathway by enhancing the dissociation of LAP from TGF- $\beta$. Furthermore, ROS promote ASK1 activation by inhibiting the association of ASK1 and Trx, leading to the activation of Smad. In addition, p53 can be phosphorylated in response to oxidative stress, leading to the formation of p53/Smad/p300 complex, which initiates the transcription of Snail, Twist and MMPs. HIF-1 $\alpha$, hypoxia-inducible factor $1 \alpha$; PHD, prolyl

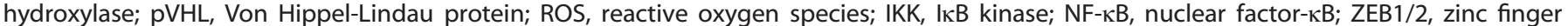
E-box binding homeobox 1/2; TGF- $\beta$, transforming growth factor $\beta$; Trx, thioredoxin; ASK1, apoptosis signal-regulating kinase 1 ; LAP, latency-associated protein; MMPs, matrix metalloproteinases.

HIF-1

In addition to NF-KB signaling, HIF-1 can also promote cancer cell EMT by activating EMT-inducing transcription factors, such as Twist, Snail and ZEB1. ${ }^{64,65}$ Recent studies have demonstrated that ROS can suppress E-cadherin expression via the HIF-1-mediated overexpression of LOX in ovarian carcinoma cells. ${ }^{66}$ Furthermore, ROS have been reported to initiate EMT via the Y654 phosphorylation of $\beta$-catenin and subsequent activation of HIF-1 signaling. ${ }^{67}$ In addition, miR373 has been reported to induce EMT in breast cancer through the ROS-mediated activation of HIF-1a. ${ }^{68}$ HIF-1 consists of two subunits: the oxygen-sensitive HIF- 1 a subunit and the constitutively expressed HIF-1 $\beta$ subunit. The $\mathrm{COOH}$-terminal (C-TAD) and $\mathrm{NH}_{2}$-terminal ( $\mathrm{N}$-TAD) domains are required for the transcriptional activity of HIF-1a. Under hypoxia, HIF-1a and HIF-1 $\beta$ form a heterodimer, which translocates into the nucleus and binds to hypoxia-response element (HRE). ${ }^{55}$ Under normoxic conditions, HIF-1a is hydroxylated on its proline residues and undergoes degradation. This process is mediated by prolyl hydroxylase (PHD), the activation of which requires $\mathrm{O}_{2}, 2$-oxoglutarate $(2-\mathrm{OG})$, and ferrous iron $\left(\mathrm{Fe}^{2+}\right)$. Under hypoxic conditions, $\mathrm{Fe}^{2+}$ is oxidized to $\mathrm{Fe}^{3+}$ by $\mathrm{ROS}$ accumulation. Concomitantly, the hydroxylation activity of PHD is inhibited, resulting in HIF-1a stabilization and subsequent activation of the HIF-1 pathway (Figure 3). ${ }^{69}$ Previous studies have suggested that PHD is not only an oxygen sensor during HIF-1a degradation but can also sense free cysteine residues. L-cysteine can activate PHD, and the oxidation of cysteine residues within its catalytic domain (Cys208, Cys266, Cys302 and Cys323/326) leads to the inactivation of PHD, indicating that free cysteine residues protect PHD from auto-oxidation. $^{70}$ The von Hippel-Lindau (VHL) tumor suppressor, which targets HIF-1a for oxygen-induced proteolysis, has also been reported to be activated by ROS. ${ }^{71}$ Recently, Axl, a member of the receptor tyrosine kinase (RTK) family, has been found to be a direct target of HIF during EMT progression. ${ }^{72}$ Genetic or pharmacological inactivation of $\mathrm{Axl}$ leads to reversal of the invasive phenotype in clear cell renal cell carcinoma. Intriguingly, a positive feedback loop exists between Axl and ROS. Axl can enhance the accumulation of ROS by activating Rac1. Accordingly, $\mathrm{H}_{2} \mathrm{O}_{2}$ treatment results in an intensive phosphorylation of $\mathrm{Axl}$ and enhances cell migration by activating the PI3K/Akt cascade. ${ }^{73}$ However, the regulatory mechanism underlying ROS-mediated AxI activation remains elusive.

\section{TGF- $\beta$}

TGF- $\beta$ is an important profibrogenic cytokine that regulates cell proliferation and cell adhesion and plays a predominant role in regulating tumor cell EMT. ${ }^{74}$ TGF- $\beta$ can suppress E-cadherin expression by activating Snail, leading to decreased adherens junctions. ${ }^{75}$ It has been proved that the activation of TGF- $\beta$ signaling can trigger EMT by decreasing fibronectin levels, whereas interfering with ROS by exogenously expressing mitochondrial thioredoxin (TXN2) reverses TGF- $\beta$-induced EMT. ${ }^{76}$ Once activated, TGF- $\beta$ can bind with type II receptor (TGF $\beta$ R-II) and subsequently activate type I receptor (TGF $\beta R-I)$, resulting in the phosphorylation of Smad2 and Smad3. Phosphorylated Smad2 and Smad3 then interact with Smad4 (Co-Smad) and translocate into the nucleus to initiate the transcription of target genes. ROS have been reported to be critical signaling intermediaries in the manipulation of TGF- $\beta$ signaling. ${ }^{77}$ For example, ROS can stimulate the phosphorylation of p53 on Ser15, leading to the formation of a p53/SMAD/p300 complex that is responsible for the transcriptional activation of TGF- $\beta^{78}$ Moreover, $\mathrm{H}_{2} \mathrm{O}_{2}$ produced by mitochondria or NOX can elevate the mRNA and protein expression of TGF- $\beta$ and activate TGF- $\beta$ signaling. ${ }^{79,80}$ Latent TGF- $\beta$ activation, a process during which secreted TGF- $\beta$ is released from latency-associated protein (LAP), is necessary for the interaction between TGF- $\beta$ and its receptors. ${ }^{77}$ Notably, it has been reported that LAP is sensitive to ROS. Oxidized LAP loses its binding capacity for TGF- $\beta$, leading to the activation of TGF- $\beta$ signaling (Figure 3 ). ${ }^{81}$ In addition, recent studies have suggested 
that activation of the TGF- $\beta / S M A D$ signaling pathway also requires ROS production. For instance, apoptosis signal-regulating kinase 1 (ASK1) can activate the TGF- $\beta$ pathway in response to ROS. ${ }^{82}$ ASK1 is a MAPKK kinase (MAPKKK) that activates the p38 MAPK pathway by phosphorylating MKKs. ${ }^{83}$ Normally, Trx binds to ASK1, leading to the ubiquitination-mediated degradation of ASK1. ${ }^{84}$ Under oxidative stress, ASK1 undergoes multimerization by forming a disulfide bond, thereby disrupting its ability to bind Trx..$^{85-87}$ These studies suggest a potential regulatory mechanism of ASK1 in TGF$\beta$ activation. Intriguingly, TGF- $\beta$ can promote ROS production via the inhibition of mitochondria complex IV and the upregulation of NOX4. ${ }^{88}$ Moreover, TGF- $\beta$ can regulate redox balance by directly disturbing the antioxidant system. Specifically, TGF- $\beta$ can promote the deletion of GSH, a major intracellular reductant, leading to imbalanced intracellular redox homeostasis. Thus, redox-regulated TGF- $\beta$ signaling orchestrates a positive feedback loop to enable EMT progression.

\section{REDOX REGULATION OF CELL MOBILITY}

EMT is characterized by increased formation of actin stress fibers and actin rearrangement, which contributes to cell directional motility. Rho GTPases are involved in actin rearrangement and can be regulated by the focal adhesion kinase (FAK), Src and PI3K/Akt signaling pathways. ${ }^{89}$ Among the Rho GTPases, RhoA promotes the formation of actin stress fibers, and Rho-associated kinase (ROCK) induces actin polymerization by cooperating with formin diaphanous 1 (DIA1). Furthermore, CDC42 and Rac1 contribute to the formation of lamellipodia and filopodia. ${ }^{90}$ Next, we will highlight the redox regulation of key proteins involved in altering cell mobility in an attempt to outline the interconnection between redox balance and cell mobility alteration.

\section{FAK}

FAK, a ubiquitously expressed non-receptor tyrosine kinase, is an important signal transduction mediator involved in cell spreading and migration through kinase-dependent or independent mechanisms. ${ }^{91,92}$ It has been reported that FAK can control cell mobility by recruiting talin to nascent adhesions. ${ }^{93}$ When cells associate with the ECM, the integrin receptor clusters, which induces FAK auto-phosphorylation at Y397, contributing to the formation of the activated FAK-Src complex. ${ }^{94}$ Following activation of $F A K$, the RhoA/ROCK pathway is activated, leading to the formation of focal adhesion (FA) and actin stress fibers. In addition, previous reports have revealed that the FAK-p130Cas complex can mediate matrix degradation by recruiting MT1-MMP to focal adhesions. ${ }^{95}$ Furthermore, FAK activation confers tumor cells with anoikis resistance by interacting with $\mathrm{Mdm} 2$ and promoting the subsequent proteasomal degradation of $\mathrm{p} 53 .{ }^{96}$ Recent studies have suggested that ROS can regulate cell mobility by modulating FAK activation. Under oxidative stress, FAK shows decreased phosphorylation through the 4-hydroxy-2-nonenal (4-HNE)dependent pathway. Antioxidants such as NAC and MPG attenuate the 4-HNE-mediated redistribution of FA and the formation of actin stress fibers. ${ }^{97}$ By contrast, ROS produced by NOXs increase $\mathrm{FAK}^{\mathrm{Y} 397}$ phosphorylation by inhibiting phosphotyrosine-phosphatase (PTP), resulting in focal adhesion stabilization and actin polymerization (Figure 4). ${ }^{98}$ However, oxidative modifications on specific cysteine residues of FAK are poorly documented, and further studies are required.

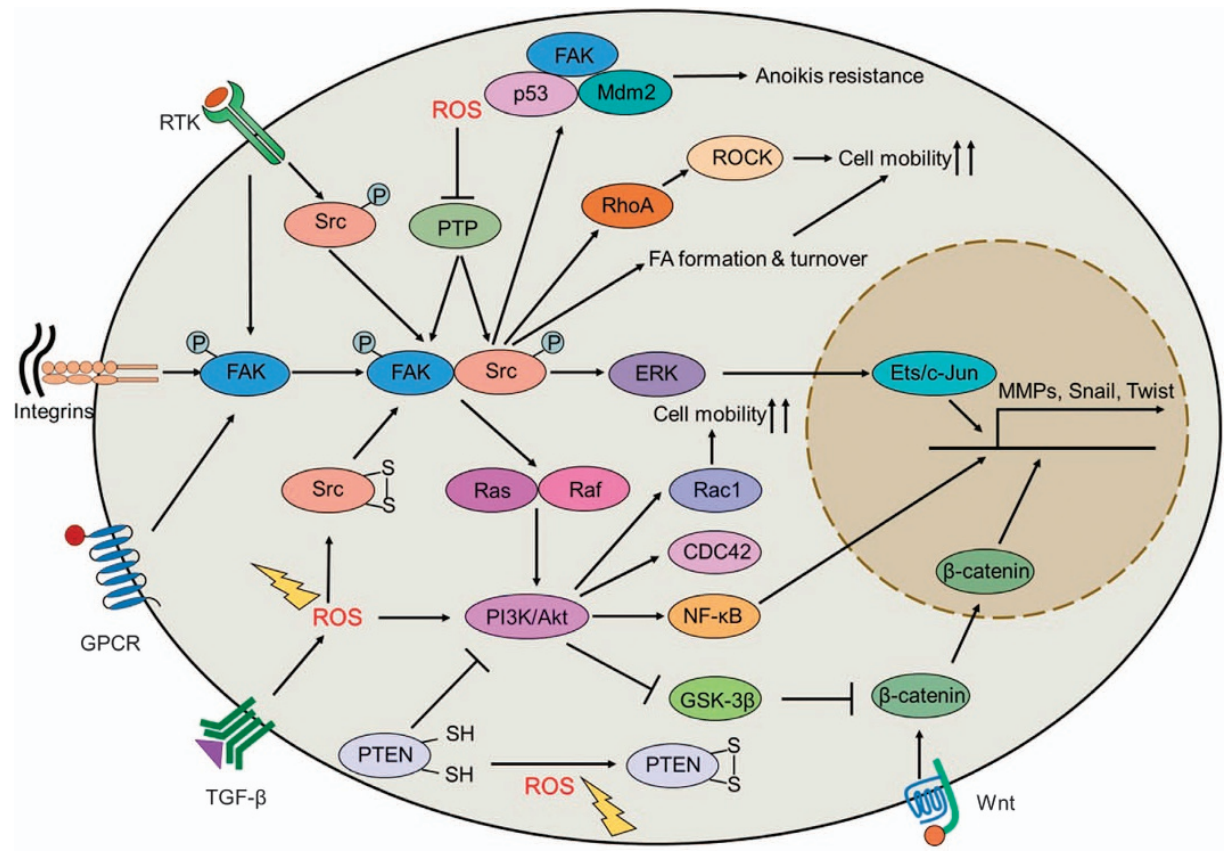

Figure 4. Redox regulation of cell mobility. ROS activate Src by inducing the formation of disulfide bonds. Activated Src binds with FAK to promote RhoA/ROCK signaling and FA formation. The Src-FAK complex also activates ERK and promotes the transcription of MMPs, Snail and Twist. Furthermore, FAK confers tumor cells with anoikis resistance by inducing Mdm2-mediated p53 degradation. In addition, PTP can also undergo oxidation and inactivation in response to oxidative stress, leading to inhibition of the FAK-Src complex. ROS inactivate PTEN by oxidative modification and activate the PI3K/Akt signaling pathway, leading to the activation of both Rac1/CDC42 and the NF-KB signaling pathways, which enhances cancer cell mobility. Moreover, the PI3K/Akt axis can inhibit GSK-3 $\beta$ activity and promote the nuclear-translocation of $\beta$-catenin, resulting in the transcription of Snail, Twist and MMPs. ROS, reactive oxygen species; FAK, focal adhesion kinase; ROCK, Rhoassociated kinase; FA, focal adhesion; ERK, extracellular signal-regulated kinases; MMPs, matrix metalloproteinases; PTP, phosphotyrosine-

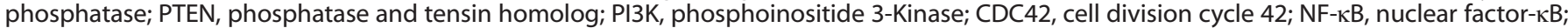
GSK-3 $\beta$, glycogen synthase kinase-3 $\beta$; MMPs, matrix metalloproteinases. 
$\operatorname{Src}$

C-Src, a member of the Src tyrosine kinase (SFK) family, plays crucial roles in regulating cell survival, proliferation and migration. ${ }^{99}$ Src is overexpressed and/or hyper-activated in various human tumors due to the dysregulation of growth factor signaling pathways (for example, EGFR, VEGFR and FGFR) and integrin engagement. Activation of Src can enhance cell movement by promoting focal adhesion turnover. Src can also promote the detachment of tumor cells from the primary tumor by downregulating E-cadherin and upregulating MMPs. Furthermore, Src also disrupts tumor cell adhesion by cooperating with MAPK and ROCK to stimulate the peripheral accumulation of phosphomyosin, thus maintaining the mesenchymal phenotype of tumor cells. $^{26,100}$ In addition, Src has been reported to phosphorylate cadherin adhesion components (such as p120-catenin) to decrease cell-cell adhesion. ${ }^{101}$ The activity of Src is dependent on the phosphorylation status of two regulatory tyrosine residues: Tyr416 and Tyr527. Tyr416 phosphorylation contributes to Src activation, whereas Tyr527 phosphorylation leads to Src inactivation. ${ }^{14}$ The phosphorylation of Tyr527 is regulated by C-terminal Src kinase (Csk) and Csk homology kinase (Chk), whereas dephosphorylation of Tyr527 is induced by PTPs, such as SH2-containing protein tyrosine phosphatase $1 / 2$ (SHP-1 and SHP-2), PEST domain-enriched tyrosine phosphatase (PEP) and low-molecular-weight protein tyrosine phosphatase (LMW-PTP). In addition to the phosphorylation/dephosphorylation regulation patterns of Src, the activity of Src can also be monitored by intracellular ROS. Src possesses 5 conserved cysteine residues (Cys238, 245, 400, 487 and 498), of which two (Cys245 and Cys487) are responsible for its oxidative activation in response to ROS. Cys245 (in the SH2 domain) and Cys487 (in the kinase domain) can form an intramolecular disulfide bond to reinforce an active conformation (Figure 4). ${ }^{102}$ Recent studies have shown that tumor suppressor B-cell translocation gene 2 (BTG2) can inhibit Src-FAK signaling by decreasing the mitochondria-derived ROS levels in prostate cancer cells. ${ }^{103}$ In addition, the obliteration of NOXgenerated ROS can also inactivate Src, which consequently influences cell mobility by restricting the phosphorylation and localization of Ezrin. ${ }^{104}$ Previous studies have suggested that a high ratio of $\mathrm{O}_{2}^{--}$to $\mathrm{H}_{2} \mathrm{O}_{2}$ leads to the oxidation-mediated activation of $\mathrm{Src}$, thus conferring anoikis resistance by activating the PI3K/PKBa and ERK pro-survival pathways. ${ }^{105}$ Reversible oxidation has emerged as an important mechanism for regulating the activity of PTPs, including SHP-1, SHP-2 and LMW-PTP. ${ }^{106-109}$ The oxidative modification of cysteine residues in the catalytic domain of PTP leads to the inhibition of PTP, thereby enhancing Src phosphorylation. ${ }^{110-112}$ Previous studies have indicated that Cys 12 and Cys 17 can form a disulfide bond to inactivate LMW-PTP under oxidative stress, which can be rescued by treatment with reductants. $^{113}$ Therefore, the use of reductants may be a promising approach for the prevention of cancer metastasis by inhibiting Src activation.

\section{$\mathrm{PI} 3 \mathrm{~K} / \mathrm{Akt}$}

The PI3K/Akt axis can facilitate protein synthesis and promote EMT by activating the NF-KB pathway. ${ }^{114}$ In addition, PI3K plays a critical role in regulating cell mobility by recruiting Rac1 and CDC42 to the leading edges of migrating cells. ${ }^{115}$ Furthermore, activation of the PI3K/Akt pathway is closely linked with GSK-3ß inhibition, which endows the stabilization of $\beta$-catenin to activate the transcription of Slug and vimentin. ${ }^{116}$ Accumulating evidence has indicated that the PI3K/Akt pathway can be activated by ROS. ${ }^{117}$ For instance, the activity of phosphatase and tensin homolog (PTEN), a well-known negative regulator of PI3K/Akt signaling, is directly repressed by ROS. The reversible inactivation of PTEN by ROS is due to disulfide bond formation between Cys124 and Cys71 at the catalytic site, and Trx is required for deoxidation and restoration of PTEN activity. This direct oxidation results in the inhibition of PTEN activity, thus contributing to the activation of the PI3K/Akt cascade (Figure 4). ${ }^{118,119}$ The PI3K inhibitor wortmannin can impede ROS production by restricting the translocation of NOX subunits, suggesting the PI3K/Akt pathway may play a role in ROS production. ${ }^{120}$ However, the manner in which the PI3K/Akt pathway regulates ROS production is not fully understood, and further investigations are needed to reveal the redox-sensitive proteins involved in this regulatory pathway.

\section{TARGETING REDOX-REGULATED EMT FOR CANCER THERAPY}

Tumor metastasis and drug resistance are two major obstacles in cancer therapy. Recent studies have shown that EMT acts as a critical regulator for not only driving tumor metastasis but also for modulating drug resistance. For example, the differentially expressed genes between paired erlotinib-resistant and erlotinib-sensitive pancreatic cancer cells were analyzed using gene expression profiling. The results demonstrated that the expression of a set of genes implicated in EMT was altered. Further studies have shown that ZEB1 silencing enhanced the therapeutic effect of erlotinib in resistant cancer cells. ${ }^{121}$ Moreover, oxaliplatinresistant colorectal cancer cells exhibit a similar phenotype to EMT. ${ }^{122}$ Consistent with these observations, suppression of EMT enhanced the sensitivity of pancreatic cancer cells to gemcitabine. ${ }^{123}$ 5-Fluorouracil is a first-line therapeutic agent for various types of cancer. However, extended exposure to 5-fluorouracil leads to chemoresistance. Interestingly, tumor specimens from patients who have undergone more than one week of chemotherapy (combination of uracil, tegafur and 5-fluorouracil) prior to surgery displayed elevated expression levels of mesenchymal markers. ${ }^{122}$ Consistently, 5-fluorouracilresistant pancreatic adenocarcinoma cells showed significantly upregulated mesenchymal markers and enhanced invasive potential. In addition, L1CAM, a chemoresistant and invasive phenotype-associated protein, was found to be dramatically upregulated in chemoresistant pancreatic cancer cells. Further investigation showed that Slug is responsible for the upregulation of L1CAM. ${ }^{124}$ Moreover, it has been increasingly recognized that antiandrogen treatment can retard drug resistance in prostate cancer by reversing the EMT process. ${ }^{125}$ Collectively, these findings highlight the important role of EMT in regulating drug resistance and suggest potential combined therapeutic strategies for the treatment of drug-resistant cancers. ${ }^{126}$

Anoikis, originally defined by Frisch and his colleagues, is a unique version of apoptotic cell death due to ECM detachment. $^{127,128}$ During anoikis, both mitochondrial and death receptor-mediated cell death pathways are activated. Once detached from adjacent cells or the ECM, cells likely undergo anoikis to suppress the dissemination of oncogenically transformed cells. In this manner, resistance to anoikis could contribute to the survival of disseminated tumor cells (DTCs), leading to metastatic colonization. ${ }^{129}$ Therefore, key proteins involved in anoikis could potentially be drug targets for preventing tumor metastasis. ${ }^{130,131}$ Recent studies have demonstrated that ROS may also be involved in anoikis resistance. As reported by Kim's group, leukotriene B4 receptor-2 (BLT2) can induce anoikis resistance in prostate cancer cells by inducing NOX-mediated ROS accumulation, whereas treatment with DPI attenuates BLT2-promoted anoikis resistance. ${ }^{132}$ Consistently, it has been proved that ROS can activate the Src-mediated ERK and Akt signaling pathways to promote anoikis resistance. ${ }^{133}$ Collectively, these observations have led to the concept that ROS may enable the activation of pro-survival pathways, including the NF-KB and PI3K/AKT pathways, in detached cancer cells, leading to anoikis resistance and malignant transformation. 
Some hypotheses have been developed regarding the role of EMT in drug resistance. For instance, EMT could confer cancer cells with cancer stem cell (CSC)-like characteristics, ${ }^{50}$ consistent with evidence that either TGF- $\beta$ treatment or overexpression of the EMT-inducing transcription factors (Snail, Twist) increases the $\mathrm{CD}_{4} 4^{+} / \mathrm{CD} 24^{-}$subpopulation. ${ }^{134}$ Cellular differentiation markers, such as CD24, CD44 and CD133, are significantly correlated with EMT-associated markers, which are processed by the NF-kB signaling pathway. ${ }^{135}$ Previous studies have suggested that gemcitabine-treated SW1990 gemcitabine-resistant cells show high levels of EMT markers and the $\mathrm{CD} 24^{+} \mathrm{CD} 44^{+} / \mathrm{CD} 133^{+}$ratio, implying a link between cell stemness and the EMT phenotype. These changes can be reversed by p65 interference. This result suggests that EMT is an adept mechanism through which cells develop a stem-like phenotype to survive lethal stimuli. Intriguingly, it has been reported that SOD2 could reverse the conversion of $\mathrm{CD} 44^{-}$cells to $\mathrm{CD} 44^{+}$cells, suggesting that ROS may be involved in the transformation of cancer stem cell-like characteristics. ${ }^{136}$ It is worth noting that a CD44 variant (CD44v) could protect cancer cells against excessive ROS by stabilizing the cystine-glutamate transporter $\mathrm{xCT}$, which contributes to chemotherapy resistance, ${ }^{137,138}$ suggesting that targeting CD44v or xCT may sensitize cancer cells to chemotherapy. CSCs, known as 'roots' of aggressive tumors, are believed to be associated with tumorigenesis, tumor recurrence, and tumor metastasis due to their capacity for long-term self-renewal and differentiation into various tumor bulk populations, as well as their resistance to chemotherapy and ionizing radiation. ${ }^{139}$ Because chemotherapeutic agents often target tumor cells that have a rapid proliferation rate, CSCs, which are primarily quiescent and possess an accelerated DNA repair system, could survive stress induced by chemotherapeutic agents. Furthermore, CSCs exhibit high levels of multi-drug resistance (MDR) proteins (such as $A B C B 1, A B C C 1$ and $A B C G 2$ ) to decrease drug influx and promote tumor cell survival. ${ }^{140}$ In addition, pro-survival signaling pathways, such as the TGF- $\beta$, NF-KB and PI3K/Akt signaling pathways, are activated during EMT, conferring tumor cells with resistance to chemotherapeutic agent-induced death signals (Figure 5). ${ }^{141}$ Recent studies

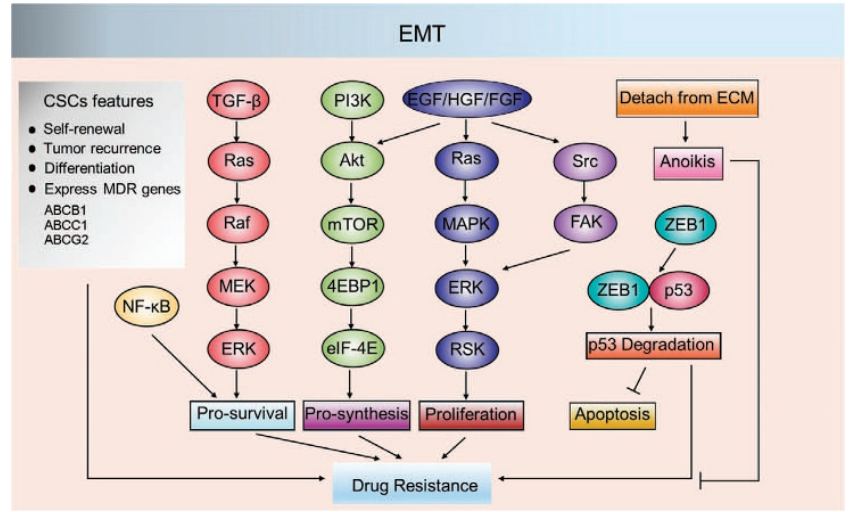

Figure 5. Regulation of drug resistance by EMT. During EMT, multiple pro-survival signaling pathways, such as TGF- $\beta$ signaling, $\mathrm{PI} 3 \mathrm{~K} /$ Akt signaling and MAPK signaling, are activated, leading to anoikis resistance and drug resistance in cancer cells. ZEB1 can induce the degradation of p53, enabling cancer cell survival during circulation in the blood. EMT also confers cancer cells with CSC features that allow cancer cells to survive stress induced by chemotherapy and radiotherapy. EMT, epithelial-mesenchymal transition; TGF- $\beta$, transforming growth factor $\beta$; PI3K, phosphoinositide 3-Kinase; MAPK, mitogen-activated protein kinase; ZEB1, zinc finger E-box binding homeobox 1; CSCs, cancer stem cells; MEK, mitogen-activated protein kinase/ERK kinase; RSK, ribosomal S6 kinase; FAK, focal adhesion kinase; ECM, extracellular matrix; EGF, Epidermal growth factor; HGF, Hepatocyte growth factor; FGF, fibroblast growth factors. have shown that CSCs exhibit low levels of ROS to maintain selfrenewal, and the advanced antioxidant capacity of CSCs confers resistance to detrimental oxidative stress induced by multiple chemotherapeutic agents (such as cisplatin, doxorubicin and arsenic trioxide).

Cancer cells possess higher levels of ROS compared with those of normal cells due to their rapid metabolic rate. ${ }^{142}$ Continuous low or moderate levels of ROS lead to the activation of several prosurvival signaling pathways. However, high levels of ROS are detrimental due to the induction of DNA damage or the activation of death-associated pathways. ${ }^{143}$ Adaptive antioxidant systems are engaged in cancer cells to counteract toxic ROS. To this end, destroying a fine-tuned antioxidant system with specific inhibitors or inducing excessive levels of ROS beyond the antioxidant capacity of cancer cells could be attractive strategies for cancer therapy. ${ }^{144}$ However, although ROS inducers have been reported to be effective in several cases, drug resistance still seems to occur. ${ }^{17}$ For example, it has been reported that daunomycin/AraC treatment contributes to the upregulation of P-glycoprotein (P-gp) in acute myeloid leukemia (AML) patients. In addition, acute increased expression of MDR1 was observed in patients with unresectable pulmonary sarcoma metastases after isolated single lung perfusion with doxorubicin was performed. ${ }^{145}$ Another study indicated that STAT3 contributes to doxorubicin resistance by upregulating SOD2 and enhancing intracellular antioxidant capacity in ABC-DLBCL cells. ${ }^{146}$

With the aim of developing novel drugs to overcome drug resistance, chemical agents to modulate redox homeostasis are being extensively studied to determine whether they can reverse the EMT process and drug resistance.

Targeting metal-mediated redox homeostasis as a therapeutic prevention for EMT

Cellular metals (for example, zinc, chromium, $\mathrm{CoCl}_{2}$ and nickel compounds) are currently attracting attention because dysregulated metal levels are associated with tumor angiogenesis, tumor cell EMT and tumor cell proliferation due to their ability to modulate ROS. ${ }^{147}$ Here, we will discuss the roles of metalregulated redox homeostasis in the EMT process of tumor cells.

Zinc is an indispensable component of copper-zinc superoxide dismutase (CuZnSOD) in the cellular antioxidant system. ${ }^{148}$ Moreover, zinc can also reduce ROS production by inhibiting the integration of the cell membrane with iron or copper. ${ }^{149}$ Notably, many critical EMT-inducing transcription factors, such as Twist, Snail and ZEB, are zinc finger proteins. ${ }^{8}$ Increasing evidence has demonstrated that the redox state is critical for regulating $\mathrm{Zn}^{2+}$ and its transporters, whereas zinc can in turn modulate cellular ROS levels. ${ }^{10}$ In lung cancer cells, zinc treatment induces EMT by increasing $\mathrm{O}_{2}^{--}$levels, which can be attenuated by MnTBAP, a specific superoxide inhibitor. ${ }^{151}$ Moreover, the zinc transporter ZIP10 (SLC39A10) has been reported to stimulate EMT by inactivating GSK-3 $\beta$ and downregulating E-cadherin. ${ }^{152}$ Another zinc transporter, LIVI, has also been identified as an important regulator of the nuclear translocation of Snail and STAT-mediated EMT. ${ }^{153}$ These observations indicate that zinc and zinc transporters regulate EMT, at least in part, by modulating the intracellular redox state. However, the underlying mechanisms by which zinc regulates cancer cell EMT still needs further investigation.

Hexavalent chromium $\left[\mathrm{Cr}^{6+}\right]$ is widely accepted as a carcinogen and is associated with lung inflammation, kidney damage and nasal ulcers. ${ }^{154-156}$ Recent studies have shown that $\mathrm{Cr}^{6+}$ can induce EMT and cell invasion to promote oncogenic transformation in lung epithelial cells. This effect is closely linked with ROS accumulation induced by $\mathrm{Cr}^{6+} .{ }^{157}$ Moreover, it has been reported that $\mathrm{Cr}^{6+}$ treatment can also induce the expression of both EMT and stem cell markers in renal epithelial HK-2 cells, which can be restored by the antioxidant vitamin $\mathrm{C}$ (Vit C). ${ }^{158}$ 
$\mathrm{CoCl}_{2}$, a hypoxia mimetic agent, can induce ROS production and nuclear localization of HIF-1a. ${ }^{159}$ It has been reported that $\mathrm{CoCl}_{2}$ treatment promotes EMT in colorectal cancer cells. Dieckol treatment reversed ROS levels and restored EMT-related morphological changes, suggesting that dieckol is a potential therapeutic for metastatic colorectal cancer. ${ }^{160}$ In line with this finding, another study showed that $\mathrm{CoCl}_{2}$ could initiate EMT in breast cancer cells. Tetraethylenepentamine (TEPA), a copper chelator, was capable of inhibiting $\mathrm{CoCl}_{2}$-induced $\mathrm{ROS}$ accumulation and EMT progression. This study suggested that copper is essential for maintaining cellular antioxidant ability, and copper chelators may be promising drugs for metastatic tumors. ${ }^{161}$

It is well documented that treatment with nickel compounds results in ROS accumulation and DNA damage that promote carcinogenesis. ${ }^{162}$ Recent studies have shown that nickel compounds can promote EMT by ROS generation and induce malignant transformation in lung cancer cells. ${ }^{163}$ Nickel induces ROS accumulation by upregulating NOX1 and SOD2 and downregulating catalase and GPX1/2. It is plausible that nickel-induced gene silencing, especially of E-cadherin, is attributed to ROS generation. ${ }^{164}$ It has been confirmed that tiron (a superoxide anion scavenger) treatment decreases cellular $\mathrm{O}_{2}^{\circ-}$ levels and restores $\mathrm{NiCl}_{2}$-induced EMT progression. Furthermore, NAC has proven to be one of the most efficient antioxidants in alleviating $\mathrm{NiCl}_{2}$-induced EMT. ${ }^{163}$ Recent studies have also revealed that nickel soluble salts can reverse nickel toxicity by upregulating the expression of $A B C B 1$, a multi-drug resistance P-gp. ${ }^{165}$

\section{Targeting redox homeostasis for EMT prevention}

Because ROS play critical roles in EMT progression, it is rational that antioxidants/ROS-inducers or inhibitors/agonists of antioxidant enzymes may hold promise for single or combinational use in cancer therapy. ${ }^{166}$ Antioxidants such as NAC, DPI, vitamin C, ebselen and MPG have been used to retard EMT progression in vitro. NAC, one of the most important antioxidants, has been demonstrated to prevent spontaneous metastasis of mouse lung carcinoma cells by repressing mitochondria-derived ROS. ${ }^{58,167}$ Furthermore, a number of natural antioxidant agents have been found to inhibit tumor metastasis. For example, apigenin can inhibit EMT to circumvent tumor migration in human hepatocellular carcinoma (HCC) cells by inactivating the NF-KB/Snail cascades. ${ }^{168}$ In addition, galangin, a flavonoid that shows anti cancer properties, can also inhibit cell invasion by restraining EMT in human renal cancer cells. ${ }^{169}$ Unlike apigenin, galangin induces ROS accumulation that leads to cell death. However, the role of ROS in galangin-suppressed EMT needs further investigation. The intracellular antioxidant system is also involved in EMT establishment. For instance, miR-212 has been reported to target manganese superoxide dismutase (MnSOD) to inhibit the invasion and pulmonary metastasis of colorectal cancer cells. ${ }^{170}$ Peroxiredoxin 1 (Prx1), another important antioxidant enzyme, has been demonstrated to affect nicotine-induced EMT in oral squamous cell carcinoma (OSCC). Silencing Prx1 resulted in inactivation of the NF-KB pathway and suppression of the EMT process, suggesting that Prx1 is a potential therapeutic target for cancer cell EMT. ${ }^{171}$ As mentioned above, EMT confers cancer cells with CSC characteristics so that they can escape from chemotherapeutic stress. CSCs exhibit well-developed antioxidant systems to buffer ROS in response to chemoradiotherapy. ${ }^{172}$ For example, overexpression of CD44v maintains low levels of ROS in CSCs by stabilizing $\mathrm{xCT}$ and promoting the uptake of cystine, an essential component of GSH synthesis. ${ }^{173}$ Therefore, targeting CD44v or xCT or enhancing cellular ROS levels beyond the threshold of CSCs may be a feasible strategy for cancer therapy. ${ }^{137,174}$ Many conventional chemotherapeutic agents can induce ROS accumulation and result in cancer cell damage due to DNA breakage. ${ }^{142}$ However, ROS accumulation also leads to EMT activation through the upregulation of MMPs, Snail and FoxOs. ${ }^{175,176}$ In addition, ROS can also activate pro-survival signaling pathways to endow cancer cells with anoikis resistance. For example, ROS activate the ligandindependent EGFR and promote the degradation of Bim (a proapoptotic protein) by the oxidative activation of $\mathrm{Src}^{133}$ By contrast, diminished glucose oxidation due to the inhibition of pyruvate dehydrogenase (PDH) attenuates oxidative stress, resulting in anoikis resistance and metastasis. ${ }^{177}$ These contradictory results suggest that the role of antioxidants in cancer therapy is complex and needs further elaboration. Recently, it has been reported that a high $\mathrm{O}_{2}^{--}$to $\mathrm{H}_{2} \mathrm{O}_{2}$ ratio is linked with anoikis resistance, and reducing this ratio sensitizes cancer cells to apoptosis. In this regard, NOX4 may emerge as a potential target because it specifically induces $\mathrm{H}_{2} \mathrm{O}_{2}$ production. 4-Me, an amino endoperoxide, can promote cell death in NOX4 overexpressed cancer cells by modulating the activity of NOX4. ${ }^{178}$ NAC or NOX4targeted siRNA can abolish the pro-apoptosis activity of 4-Me. Given the paradoxical role of ROS in cancer therapy, further studies are urgently needed to uncover the mysterious role of redox regulation in cancer progression, which will help correctly guide the redox-targeting strategy in cancer therapy.

\section{CONCLUSIONS}

Tumor metastasis is an ongoing challenge in tumor therapy. Although several signaling pathways (such as the TGF- $\beta, N F-k B$, HIF-1a signaling pathways) involved in tumor metastasis have been investigated, new insights are urgently needed to extend our understanding of the intrinsic molecular events that drive tumor cell metastasis. ${ }^{179}$ EMT, a driving force in mediating tumor cell migration, invasion and tumor progression, is responsible for tumor metastasis, as well as drug resistance, and holds the potential to be a drug target for advanced tumor therapy. ${ }^{180}$ Current studies have shown that ROS can influence the function of various key proteins involved in the EMT process through reversible or irreversible oxidative modifications on free cysteine residues. Emerging evidence suggests that ROS accumulation leads to increased cell mobility, diminished cell-cell conjunctions, remodeled cytoskeleton, downregulated epithelial cell markers, upregulated mesenchymal makers and degraded ECM. Buffering ROS using antioxidants, such as NAC and MPG, results in attenuated EMT progression. However, antioxidant treatment may lead to the survival of CSCs and DTCs, implying a dual role of antioxidants in cancer therapy. Interestingly, as mentioned above, different types of ROS seem to have alternative effects on EMT, suggesting that specific inhibitors or inducers of ROS may have different functions. Thus, further studies are required to elucidate these underlying mechanisms. Furthermore, ROS generated from different sources (NOX, 5-LOX, or mitochondria) may contribute to distinct outcomes, further supporting the need to comprehensively understand the regulatory mechanisms underlying ROS. Targeting redox regulation for preventing EMT and tumor metastasis is clearly promising. However, redox-based strategies may play dual roles in cancer therapy as redox modulators themselves may lead to drug resistance. In this regard, combining redox modulators with conventional chemotherapy may benefit therapeutic efficacy.

\section{ACKNOWLEDGEMENTS}

This work was supported by grants from the National 973 Basic Research Program of China (2013CB911300), the Chinese NSFC (81430071, 81672381 and 81602194) and the National Key Research and development program of China (2016YFC1200203).

\section{COMPETING INTEREST}

The authors declare no conflict of interest. 


\section{REFERENCES}

1 Hay ED. An overview of epithelio-mesenchymal transformation. Acta Anat (Basel) 1995; 154: 820.

2 Kalluri R, Weinberg RA. The basics of epithelial-mesenchymal transition. J Clin Invest 2009; 119: 1420-1428.

3 Wu Y, Deng J, Rychahou PG, Qiu S, Evers BM, Zhou BP. Stabilization of snail by NF-kappaB is required for inflammation-induced cell migration and invasion. Cancer Cell 2009; 15: 416-428.

4 Nieto MA. Epithelial plasticity: a common theme in embryonic and cancer cells. Science 2013; 342: 1234850.

5 Grande MT, Sanchez-Laorden B, Lopez-Blau C, De Frutos CA, Boutet A, Arevalo M et al. Snail1-induced partial epithelial-to-mesenchymal transition drives renal fibrosis in mice and can be targeted to reverse established disease. Nat Med 2015; 21: 989-997.

6 Tsai JH, Yang J. Epithelial-mesenchymal plasticity in carcinoma metastasis. Genes Dev 2013; 27: 2192-2206.

7 Giannoni E, Parri M, Chiarugi P. EMT and oxidative stress: a bidirectional interplay affecting tumor malignancy. Antioxid Redox Signal 2012; 16: 1248-1263.

8 Lamouille S, Xu J, Derynck R. Molecular mechanisms of epithelial-mesenchymal transition. Nat Rev Mol Cell Biol 2014; 15: 178-196.

9 Ye X, Weinberg RA. Epithelial-Mesenchymal Plasticity: A Central Regulator of Cancer Progression. Trends Cell Biol 2015; 25: 675-686.

10 Cannito S, Novo E, di Bonzo LV, Busletta C, Colombatto S, Parola M. Epithelialmesenchymal transition: from molecular mechanisms, redox regulation to implications in human health and disease. Antioxid Redox Signal 2010; 12: 1383-1430.

11 Tam WL, Weinberg RA. The epigenetics of epithelial-mesenchymal plasticity in cancer. Nat Med 2013; 19: 1438-1449.

12 Kessenbrock K, Plaks V, Werb Z. Matrix metalloproteinases: regulators of the tumor microenvironment. Cell 2010; 141: 52-67.

13 Ghahhari NM, Babashah S. Interplay between microRNAs and WNT/beta-catenin signalling pathway regulates epithelial-mesenchymal transition in cancer. Eur $\mathrm{J}$ Cancer 2015; 51: 1638-1649.

14 Zhang $\mathrm{H}$, Forman HJ. TGFbeta1 rapidly activates Src through a non-canonical redox mechanism. Free Radic Biol Med 2014; 75: S4.

15 Loo SY, Hirpara JL, Pandey V, Tan TZ, Yap CT, Lobie PE et al. Manganese Superoxide Dismutase Expression Regulates the Switch Between an Epithelial and a Mesenchymal-Like Phenotype in Breast Carcinoma. Antioxid Redox Signal 2016; 25: 283-299.

16 Xu X, Sun S, Xie F, Ma J, Tang J, He S et al. Advanced Oxidation Protein Products Induce Epithelial-Mesenchymal Transition of Intestinal Epithelial Cells via a PKC delta-Mediated, Redox-Dependent Signaling Pathway. Antioxid Redox Signal 2017; 27: 37-56.

17 Kuo MT. Redox regulation of multidrug resistance in cancer chemotherapy: molecular mechanisms and therapeutic opportunities. Antioxid Redox Signal 2009; 11: 99-133.

18 Zorov DB, Juhaszova M, Sollott SJ. Mitochondrial reactive oxygen species (ROS) and ROS-induced ROS release. Physiol Rev 2014; 94: 909-950.

19 Chiu J, Dawes IW. Redox control of cell proliferation. Trends Cell Biol 2012; 22: 592-601.

20 Hurd TR, DeGennaro M, Lehmann R. Redox regulation of cell migration and adhesion. Trends Cell Biol 2012; 22: 107-115.

21 Liu Y, Li Q, Zhou L, Xie N, Nice EC, Zhang H et al. Cancer drug resistance: redox resetting renders a way. Oncotarget 2016; 7: 42740-42761.

22 Jiang J, Wang K, Nice EC, Zhang T, Huang C. High-throughput screening of cellular redox sensors using modern redox proteomics approaches. Expert Rev Proteomics 2015; 12: 543-555.

23 Yilmaz M, Christofori G. EMT, the cytoskeleton, and cancer cell invasion. Cancer Metastasis Rev 2009; 28: 15-33.

24 Alanko J, Ivaska J. Endosomes: Emerging Platforms for Integrin-Mediated FAK Signalling. Trends Cell Biol 2016; 26: 391-398.

25 Parsons JT, Horwitz AR, Schwartz MA. Cell adhesion: integrating cytoskeletal dynamics and cellular tension. Nat Rev Mol Cell Biol 2010; 11: 633-643.

26 Canel M, Serrels A, Frame MC, Brunton VG. E-cadherin-integrin crosstalk in cancer invasion and metastasis. J Cell Sci 2013; 126: 393-401.

27 de Rezende FF, Martins Lima A, Niland S, Wittig I, Heide H, Schroder K et al. Integrin alpha7beta1 is a redox-regulated target of hydrogen peroxide in vascular smooth muscle cell adhesion. Free Radic Biol Med 2012; 53: 521-531.

28 Urban P, Vuaroqueaux V, Labuhn M, Delorenzi M, Wirapati P, Wight E et al. Increased expression of urokinase-type plasminogen activator mRNA determines adverse prognosis in ErbB2-positive primary breast cancer. J Clin Oncol 2006; 24: 4245-4253.

29 Lee KH, Kim SW, Kim JR. Reactive oxygen species regulate urokinase plasminogen activator expression and cell invasion via mitogen-activated protein kinase pathways after treatment with hepatocyte growth factor in stomach cancer cells. J Exp Clin Cancer Res 2009; 28: 73.

30 Tran $\mathrm{H}$, Maurer F, Nagamine Y. Stabilization of urokinase and urokinase receptor mRNAs by HuR is linked to its cytoplasmic accumulation induced by activated mitogen-activated protein kinase-activated protein kinase 2. Mol Cell Biol 2003; 23: 7177-7188.

31 Mehta M, Basalingappa K, Griffith JN, Andrade D, Babu A, Amreddy N et al. HuR silencing elicits oxidative stress and DNA damage and sensitizes human triplenegative breast cancer cells to radiotherapy. Oncotarget 2016; 7: 64820-64835.

32 Gu S, Liu Y, Zhu B, Ding K, Yao TP, Chen F et al. Loss of alpha-Tubulin Acetylation Is Associated with TGF-beta-induced Epithelial-Mesenchymal Transition. J Biol Chem 2016; 291: 5396-5405.

33 Leduc C, Etienne-Manneville S. Intermediate filaments in cell migration and invasion: the unusual suspects. Curr Opin Cell Biol 2015; 32: 102-112.

34 Moldovan L, Moldovan NI, Sohn RH, Parikh SA, Goldschmidt-Clermont PJ. Redox changes of cultured endothelial cells and actin dynamics. Circ Res 2000; 86: 549-557.

35 DalleDonne I, Milzani A, Colombo R. H2O2-treated actin: assembly and polymer interactions with cross-linking proteins. Biophys J 1995; 69: 2710-2719.

36 Lassing I, Schmitzberger F, Bjornstedt M, Holmgren A, Nordlund P, Schutt CE et al. Molecular and structural basis for redox regulation of beta-actin. $J \mathrm{Mol} B i o l$ 2007; 370: 331-348.

37 Lundquist MR, Storaska AJ, Liu TC, Larsen SD, Evans T, Neubig RR et al. Redox modification of nuclear actin by MICAL-2 regulates SRF signaling. Cell 2014; 156 : 563-576.

38 Grintsevich EE, Yesilyurt HG, Rich SK, Hung RJ, Terman JR, Reisler E. F-actin dismantling through a redox-driven synergy between Mical and cofilin. Nat Cell Biol 2016; 18: 876-885.

39 Aberle H. Redox switch for actin. Nat Cell Biol 2013; 15: 1403-1404.

40 Duggin IG, Aylett CH, Walsh JC, Michie KA, Wang Q, Turnbull L et al. CetZ tubulinlike proteins control archaeal cell shape. Nature 2015; 519: 362-365.

41 Landino LM, Hagedorn TD, Kennett KL. Evidence for thiol/disulfide exchange reactions between tubulin and glyceraldehyde-3-phosphate dehydrogenase. Cytoskeleton 2014; 71: 707-718.

42 Li WD, Zhao YZ, Chou IN. Paraquat-induced cytoskeletal injury in cultured cells. Toxicol Appl Pharmacol 1987; 91: 96-106.

43 Friedl P, Gilmour D. Collective cell migration in morphogenesis, regeneration and cancer. Nat Rev Mol Cell Biol 2009; 10: 445-457.

$44 \mathrm{Kim}$ JS, Huang TY, Bokoch GM. Reactive oxygen species regulate a slingshotcofilin activation pathway. Mol Biol Cell 2009; 20: 2650-2660.

45 Taulet N, Delorme-Walker VD, DerMardirossian C. Reactive oxygen species regulate protrusion efficiency by controlling actin dynamics. PLoS One 2012; 7: e41342.

46 Fiaschi T, Cozzi G, Raugei G, Formigli L, Ramponi G, Chiarugi P. Redox regulation of beta-actin during integrin-mediated cell adhesion. J Biol Chem 2006; 281 22983-22991.

47 Friedl P, Alexander S. Cancer invasion and the microenvironment: plasticity and reciprocity. Cell 2011; 147: 992-1009.

48 Mayor R, Etienne-Manneville S. The front and rear of collective cell migration Nat Rev Mol Cell Biol 2016; 17: 97-109.

49 Zihni C, Mills C, Matter K, Balda MS. Tight junctions: from simple barriers to multifunctional molecular gates. Nat Rev Mol Cell Biol 2016; 17: 564-580.

50 Mimeault M, Batra SK. Altered gene products involved in the malignant reprogramming of cancer stem/progenitor cells and multitargeted therapies. Mol Aspects Med 2014; 39: 3-32.

51 El-Naggar AM, Veinotte CJ, Cheng H, Grunewald TG, Negri GL, Somasekharan SP et al. Translational Activation of HIF1alpha by YB-1 Promotes Sarcoma Metastasis. Cancer Cell 2015; 27: 682-697.

52 Gupta S, Maitra A. EMT: Matter of Life or Death? Cell 2016; 164: 840-842.

53 Morgan MJ, Liu ZG. Crosstalk of reactive oxygen species and NF-kappaB signaling. Cell Res 2011; 21: 103-115.

54 Blaser H, Dostert C, Mak TW, Brenner D. TNF and ROS Crosstalk in Inflammation. Trends Cell Biol 2016; 26: 249-261.

55 Napetschnig J, Wu H. Molecular basis of NF-kappaB signaling. Annu Rev Biophys 2013; 42: 443-468.

56 Min C, Eddy SF, Sherr DH, Sonenshein GE. NF-kappaB and epithelial to mesenchymal transition of cancer. J Cell Biochem 2008; 104: 733-744.

57 Inumaru J, Nagano O, Takahashi E, Ishimoto T, Nakamura S, Suzuki Y et al. Molecular mechanisms regulating dissociation of cell-cell junction of epithelial cells by oxidative stress. Genes Cells 2009; 14: 703-716.

58 Shimojo $\mathrm{Y}$, Akimoto $\mathrm{M}$, Hisanaga T, Tanaka T, Tajima $\mathrm{Y}$, Honma $\mathrm{Y}$ et al. Attenuation of reactive oxygen species by antioxidants suppresses hypoxiainduced epithelial-mesenchymal transition and metastasis of pancreatic cancer cells. Clin Exp Metastasis 2013; 30: 143-154. 
59 Cichon MA, Radisky DC. ROS-induced epithelial-mesenchymal transition in mammary epithelial cells is mediated by NF-kB-dependent activation of Snail. Oncotarget 2014; 5: 2827-2838.

60 Li W, Cao L, Han L, Xu Q, Ma Q. Superoxide dismutase promotes the epithelialmesenchymal transition of pancreatic cancer cells via activation of the $\mathrm{H}_{2} \mathrm{O} 2 /$ ERK/NF-kappaB axis. Int J Oncol 2015; 46: 2613-2620.

61 Nathan C, Cunningham-Bussel A. Beyond oxidative stress: an immunologist's guide to reactive oxygen species. Nat Rev Immunol 2013; 13: 349-361.

62 Herscovitch M, Comb W, Ennis T, Coleman K, Yong S, Armstead B et al. Intermolecular disulfide bond formation in the NEMO dimer requires Cys54 and Cys347. Biochem Biophys Res Commun 2008; 367: 103-108.

63 Lee DF, Kuo HP, Liu M, Chou CK, Xia W, Du Y et al. KEAP1 E3 ligase-mediated downregulation of NF-kappaB signaling by targeting IKKbeta. Mol Cell 2009; 36: 131-140.

64 Joseph JV, Conroy S, Pavlov K, Sontakke P, Tomar T, Eggens-Meijer E et al. Hypoxia enhances migration and invasion in glioblastoma by promoting a mesenchymal shift mediated by the HIF1alpha-ZEB1 axis. Cancer Lett 2015; 359: 107-116.

65 Zhang W, Shi X, Peng Y, Wu M, Zhang P, Xie R et al. HIF-1alpha Promotes Epithelial-Mesenchymal Transition and Metastasis through Direct Regulation of ZEB1 in Colorectal Cancer. PLoS One 2015; 10: e0129603.

66 Wang Y, Ma J, Shen H, Wang C, Sun Y, Howell SB et al. Reactive oxygen species promote ovarian cancer progression via the HIF-1alpha/LOX/E-cadherin pathway. Oncol Rep 2014; 32: 2150-2158.

67 Xi Y, Wei Y, Sennino B, Ulsamer A, Kwan I, Brumwell AN et al. Identification of pY654-beta-catenin as a critical co-factor in hypoxia-inducible factor-1alpha signaling and tumor responses to hypoxia. Oncogene 2013; 32: 5048-5057.

68 Chen D, Dang BL, Huang JZ, Chen M, Wu D, Xu ML et al. MiR-373 drives the epithelial-to-mesenchymal transition and metastasis via the miR-373-TXNIPHIF1alpha-TWIST signaling axis in breast cancer. Oncotarget 2015; 6: 32701-32712.

69 Hielscher A, Gerecht S. Hypoxia and free radicals: role in tumor progression and the use of engineering-based platforms to address these relationships. Free Radic Biol Med 2015; 79: 281-291.

70 Briggs KJ, Koivunen P, Cao S, Backus KM, Olenchock BA, Patel H et al. Paracrine Induction of HIF by Glutamate in Breast Cancer: EgIN1 Senses Cysteine. Cell 2016; 166: 126-139.

71 Chetram MA, Bethea DA, Odero-Marah VA, Don-Salu-Hewage AS, Jones KJ, Hinton CV. ROS-mediated activation of AKT induces apoptosis via pVHL in prostate cancer cells. Mol Cell Biochem 2013; 376: 63-71.

72 Rankin EB, Fuh KC, Castellini L, Viswanathan K, Finger EC, Diep AN et al. Direct regulation of GAS6/AXL signaling by HIF promotes renal metastasis through SRC and MET. Proc Natl Acad Sci USA 2014; 111: 13373-13378.

73 Huang JS, Cho CY, Hong CC, Yan MD, Hsieh MC, Lay JD et al. Oxidative stress enhances Axl-mediated cell migration through an Akt1/Rac1-dependent mechanism. Free Radic Biol Med 2013; 65: 1246-1256.

74 Katsuno Y, Lamouille S, Derynck R. TGF-beta signaling and epithelialmesenchymal transition in cancer progression. Curr Opin Oncol 2013; 25: 76-84.

75 Naber HP, Drabsch Y, Snaar-Jagalska BE, ten Dijke P, van Laar T. Snail and Slug, key regulators of TGF-beta-induced EMT, are sufficient for the induction of single-cell invasion. Biochem Biophys Res Commun 2013; 435: 58-63.

76 Ishikawa F, Kaneko E, Sugimoto T, Ishijima T, Wakamatsu M, Yuasa A et al. A mitochondrial thioredoxin-sensitive mechanism regulates TGF-beta-mediated gene expression associated with epithelial-mesenchymal transition. Biochem Biophys Res Commun 2014; 443: 821-827.

77 Liu RM, Desai LP. Reciprocal regulation of TGF-beta and reactive oxygen species: A perverse cycle for fibrosis. Redox Biol 2015; 6: 565-577.

78 Overstreet JM, Samarakoon R, Meldrum KK, Higgins PJ. Redox control of p53 in the transcriptional regulation of TGF-beta1 target genes through SMAD cooperativity. Cell Signal 2014; 26: 1427-1436.

79 Shvedova AA, Kisin ER, Murray AR, Kommineni C, Castranova V, Fadeel B et al. Increased accumulation of neutrophils and decreased fibrosis in the lung of NADPH oxidase-deficient C57BL/6 mice exposed to carbon nanotubes. Toxicol Appl Pharmacol 2008; 231: 235-240.

80 Jaffer OA, Carter AB, Sanders PN, Dibbern ME, Winters CJ, Murthy S et al. Mitochondrial-targeted antioxidant therapy decreases transforming growth factor-beta-mediated collagen production in a murine asthma model. Am J Respir Cell Mol Biol 2015; 52: 106-115.

81 Pociask DA, Sime PJ, Brody AR. Asbestos-derived reactive oxygen species activate TGF-beta1. Lab Invest 2004; 84: 1013-1023.

82 Seong HA, Manoharan R, Ha H. Coordinate Activation of Redox-Dependent ASK1/TGF-beta Signaling by a Multiprotein Complex (MPK38, ASK1, SMADs, ZPR9, and TRX) Improves Glucose and Lipid Metabolism in Mice. Antioxid Redox Signal 2016; 24: 434-452.
83 Ichijo H, Nishida E, Irie K, ten Dijke P, Saitoh M, Moriguchi T et al. Induction of apoptosis by ASK1, a mammalian MAPKKK that activates SAPK/JNK and p38 signaling pathways. Science 1997; 275: 90-94.

84 Zhang L, Wang K, Lei Y, Li Q, Nice EC, Huang C. Redox signaling: Potential arbitrator of autophagy and apoptosis in therapeutic response. Free Radic Biol Med 2015; 89: 452-465.

85 Gotoh Y, Cooper JA. Reactive oxygen species- and dimerization-induced activation of apoptosis signal-regulating kinase 1 in tumor necrosis factor-alpha signal transduction. J Biol Chem 1998; 273: 17477-17482.

86 Liu Y, Min W. Thioredoxin promotes ASK1 ubiquitination and degradation to inhibit ASK1-mediated apoptosis in a redox activity-independent manner. Circ Res 2002; 90: 1259-1266.

87 Nadeau PJ, Charette SJ, Toledano MB, Landry J. Disulfide Bond-mediated multimerization of Ask1 and its reduction by thioredoxin-1 regulate $\mathrm{H}(2) \mathrm{O}(2)$ induced c-Jun $\mathrm{NH}(2)$-terminal kinase activation and apoptosis. Mol Biol Cell 2007; 18: $3903-3913$.

88 Yoon YS, Lee JH, Hwang SC, Choi KS, Yoon G. TGF beta1 induces prolonged mitochondrial ROS generation through decreased complex IV activity with senescent arrest in Mv1Lu cells. Oncogene 2005; 24: 1895-1903.

89 Cai L, Ye Y, Jiang Q, Chen Y, Lyu X, Li J et al. Epstein-Barr virus-encoded microRNA BART1 induces tumour metastasis by regulating PTEN-dependent pathways in nasopharyngeal carcinoma. Nat Commun 2015; 6: 7353.

90 Narumiya S, Tanji M, Ishizaki T. Rho signaling, ROCK and mDia1, in transformation, metastasis and invasion. Cancer Metastasis Rev 2009; 28: 65-76.

91 Mitra SK, Schlaepfer DD. Integrin-regulated FAK-Src signaling in normal and cancer cells. Curr Opin Cell Biol 2006; 18: 516-523.

92 Tomar A, Schlaepfer DD. Focal adhesion kinase: switching between GAPs and GEFs in the regulation of cell motility. Curr Opin Cell Biol 2009; 21: 676-683.

93 Lawson C, Lim ST, Uryu S, Chen XL, Calderwood DA, Schlaepfer DD. FAK promotes recruitment of talin to nascent adhesions to control cell motility. J Cell Biol 2012; 196: 223-232.

94 Sulzmaier FJ, Jean C, Schlaepfer DD. FAK in cancer: mechanistic findings and clinical applications. Nat Rev Cancer 2014; 14: 598-610.

95 Wang Y, McNiven MA. Invasive matrix degradation at focal adhesions occurs via protease recruitment by a FAK-p130Cas complex. J Cell Biol 2012; 196: 375-385.

$96 \operatorname{Lim} \mathrm{ST}$, Chen XL, Lim Y, Hanson DA, Vo T, Howerton $\mathrm{K}$ et al. Nuclear FAK promotes cell proliferation and survival through FERM-enhanced p53 degradation. Mol Cell 2008; 29: 9-22.

97 Usatyuk PV, Parinandi NL, Natarajan V. Redox regulation of 4-hydroxy-2-nonenalmediated endothelial barrier dysfunction by focal adhesion, adherens, and tight junction proteins. J Biol Chem 2006; 281: 35554-35566.

98 Ribeiro-Pereira C, Moraes JA, Souza Mde J, Laurindo FR, Arruda MA, Barja-Fidalgo C. Redox modulation of FAK controls melanoma survival--role of NOX4. PLoS One 2014; 9: e99481.

99 Giannoni E, Chiarugi P. Redox circuitries driving Src regulation. Antioxid Redox Signal 2014; 20: 2011-2025.

100 Avizienyte E, Fincham VJ, Brunton VG, Frame MC. Src SH3/2 domain-mediated peripheral accumulation of Src and phospho-myosin is linked to deregulation of E-cadherin and the epithelial-mesenchymal transition. Mol Biol Cell 2004; 15: 2794-2803.

101 Hong JY, Oh IH, McCrea PD. Phosphorylation and isoform use in p120-catenin during development and tumorigenesis. Biochim Biophys Acta 2016; 1863: 102-114.

102 Giannoni E, Buricchi F, Raugei G, Ramponi G, Chiarugi P. Intracellular reactive oxygen species activate Src tyrosine kinase during cell adhesion and anchoragedependent cell growth. Mol Cell Biol 2005; 25: 6391-6403.

103 Lim SK, Choi YW, Lim IK, Park TJ. BTG2 suppresses cancer cell migration through inhibition of Src-FAK signaling by downregulation of reactive oxygen species generation in mitochondria. Clin Exp Metastasis 2012; 29: 901-913.

104 Corcoran A, Cotter TG. FLT3-driven redox-modulation of Ezrin regulates leukaemic cell migration. Free Radic Res 2013; 47: 20-34.

105 Zhu P, Tan MJ, Huang RL, Tan CK, Chong HC, Pal M et al. Angiopoietin-like 4 protein elevates the prosurvival intracellular $\mathrm{O} 2(-): \mathrm{H} 2 \mathrm{O} 2$ ratio and confers anoikis resistance to tumors. Cancer Cell 2011; 19: 401-415.

106 Fuhrmann J, Subramanian V, Thompson PR. Targeting the arginine phosphatase YwIE with a catalytic redox-based inhibitor. ACS Chem Biol 2013; 8: 2024-2032.

107 Hiraga R, Kato M, Miyagawa S, Kamata T. Nox4-derived ROS signaling contributes to TGF-beta-induced epithelial-mesenchymal transition in pancreatic cancer cells. Anticancer Res 2013; 33: 4431-4438.

108 Frijhoff J, Dagnell M, Godfrey R, Ostman A. Regulation of protein tyrosine phosphatase oxidation in cell adhesion and migration. Antioxid Redox Signal 2014; 20: 1994-2010

109 Jang JY, Min JH, Chae YH, Baek JY, Wang SB, Park SJ et al. Reactive oxygen species play a critical role in collagen-induced platelet activation via SHP-2 oxidation. Antioxid Redox Signal 2014; 20: 2528-2540. 
110 Taddei ML, Parri M, Mello T, Catalano A, Levine AD, Raugei G et al. Integrinmediated cell adhesion and spreading engage different sources of reactive oxygen species. Antioxid Redox Signal 2007; 9: 469-481.

111 Weibrecht I, Bohmer SA, Dagnell M, Kappert K, Ostman A, Bohmer FD. Oxidation sensitivity of the catalytic cysteine of the protein-tyrosine phosphatases SHP-1 and SHP-2. Free Radic Biol Med 2007; 43: 100-110.

112 Wang SB, Jang JY, Chae YH, Min JH, Baek JY, Kim M et al. Kaempferol suppresses collagen-induced platelet activation by inhibiting NADPH oxidase and protecting SHP-2 from oxidative inactivation. Free Radic Biol Med 2015; 83: 41-53.

113 Chiarugi P, Fiaschi T, Taddei ML, Talini D, Giannoni E, Raugei G et al. Two vicinal cysteines confer a peculiar redox regulation to low molecular weight protein tyrosine phosphatase in response to platelet-derived growth factor receptor stimulation. J Biol Chem 2001; 276: 33478-33487.

114 Dibble CC, Cantley LC. Regulation of mTORC1 by PI3K signaling. Trends Cell Biol 2015; 25: 545-555.

115 Nelson WJ. Remodeling epithelial cell organization: transitions between frontrear and apical-basal polarity. Cold Spring Harb Perspect Biol 2009; 1: a000513.

116 Prasad CP, Rath G, Mathur S, Bhatnagar D, Parshad R, Ralhan R. Expression analysis of E-cadherin, Slug and GSK3beta in invasive ductal carcinoma of breast. BMC Cancer 2009; 9: 325.

117 Nakanishi A, Wada Y, Kitagishi Y, Matsuda S. Link between PI3K/AKT/PTEN Pathway and NOX Proteinin Diseases. Aging Dis 2014; 5: 203-211.

118 Lee SR, Yang KS, Kwon J, Lee C, Jeong W, Rhee SG. Reversible inactivation of the tumor suppressor PTEN by H2O2. J Biol Chem 2002; 277: 20336-20342.

119 Kwon J, Lee SR, Yang KS, Ahn Y, Kim YJ, Stadtman ER et al. Reversible oxidation and inactivation of the tumor suppressor PTEN in cells stimulated with peptide growth factors. Proc Natl Acad Sci USA 2004; 101: 16419-16424.

120 Ngkelo A, Meja K, Yeadon M, Adcock I, Kirkham PA. LPS induced inflammatory responses in human peripheral blood mononuclear cells is mediated through NOX4 and Gialpha dependent PI-3kinase signalling. J Inflamm 2012; 9: 1.

121 Arumugam T, Ramachandran V, Fournier KF, Wang H, Marquis L, Abbruzzese J et al. Epithelial to mesenchymal transition contributes to drug resistance in pancreatic cancer. Cancer Res 2009; 69: 5820-5828.

122 Kawamoto A, Yokoe T, Tanaka K, Saigusa S, Toiyama Y, Yasuda H et al. Radiation induces epithelial-mesenchymal transition in colorectal cancer cells. Oncol Rep 2012; 27: 51-57.

123 Zheng X, Carstens JL, Kim J, Scheible M, Kaye J, Sugimoto H et al. Epithelial-tomesenchymal transition is dispensable for metastasis but induces chemoresistance in pancreatic cancer. Nature 2015; 527: 525-530.

124 Lund K, Dembinski JL, Solberg N, Urbanucci A, Mills IG, Krauss S. Slug-dependent upregulation of L1CAM is responsible for the increased invasion potential of pancreatic cancer cells following long-term 5-FU treatment. PLoS One 2015; 10: e0123684.

125 Martin SK, Pu H, Penticuff JC, Cao Z, Horbinski C, Kyprianou N. Multinucleation and mesenchymal-to-epithelial transition alleviate resistance to combined cabazitaxel and antiandrogen therapy in advanced prostate cancer. Cancer Res 2016; 76: 912-926.

$126 \mathrm{Du}$ B, Shim JS. Targeting epithelial-mesenchymal transition (EMT) to overcome drug resistance in cancer. Molecules 2016; 21 (pii): E965.

127 Frisch SM, Ruoslahti E. Integrins and anoikis. Curr Opin Cell Biol 1997; 9: 701-706.

128 Frisch SM, Screaton RA. Anoikis mechanisms. Curr Opin Cell Biol 2001; 13: $555-562$

129 Peng YF, Shi YH, Ding ZB, Ke AW, Gu CY, Hui B et al. Autophagy inhibition suppresses pulmonary metastasis of $\mathrm{HCC}$ in mice via impairing anoikis resistance and colonization of HCC cells. Autophagy 2013; 9: 2056-2068.

130 Sakamoto S, Kyprianou N. Targeting anoikis resistance in prostate cancer metastasis. Mol Aspects Med 2010; 31: 205-214.

131 Kenific CM, Debnath J. Cellular and metabolic functions for autophagy in cancer cells. Trends Cell Biol 2015; 25: 37-45.

132 Lee JW, Kim JH. Activation of the leukotriene B4 receptor 2-reactive oxygen species (BLT2-ROS) cascade following detachment confers anoikis resistance in prostate cancer cells. J Biol Chem 2013; 288: 30054-30063.

133 Giannoni E, Buricchi F, Grimaldi G, Parri M, Cialdai F, Taddei ML et al. Redox regulation of anoikis: reactive oxygen species as essential mediators of cell survival. Cell Death Differ 2008; 15: 867-878.

134 Mani SA, Guo W, Liao MJ, Eaton EN, Ayyanan A, Zhou AY et al. The epithelialmesenchymal transition generates cells with properties of stem cells. Cell 2008; 133: 704-715.

135 Zhang Y, Wei J, Wang H, Xue X, An Y, Tang D et al. Epithelial mesenchymal transition correlates with CD24+CD44+ and CD133+ cells in pancreatic cancer. Oncol Rep 2012; 27: 1599-1605.

136 Kinugasa H, Whelan KA, Tanaka K, Natsuizaka M, Long A, Guo A et al. Mitochondrial SOD2 regulates epithelial-mesenchymal transition and cell populations defined by differential CD44 expression. Oncogene 2015; 34: 5229-5239.
137 Ishimoto T, Nagano O, Yae T, Tamada M, Motohara T, Oshima H et al. CD44 variant regulates redox status in cancer cells by stabilizing the $\mathrm{XCT}$ subunit of system $x \mathrm{C}(-)$ and thereby promotes tumor growth. Cancer Cell 2011; 19: 387-400.

138 Thanee M, Loilome W, Techasen A, Sugihara E, Okazaki S, Abe S et al. CD44 variant-dependent redox status regulation in liver fluke-associated cholangiocarcinoma: A target for cholangiocarcinoma treatment. Cancer Sci 2016; 107: 991-1000.

139 Frank NY, Schatton T, Frank MH. The therapeutic promise of the cancer stem cell concept. J Clin Invest 2010; 120: 41-50.

140 Markman JL, Rekechenetskiy A, Holler E, Ljubimova JY. Nanomedicine therapeutic approaches to overcome cancer drug resistance. Adv Drug Deliv Rev 2013; 65: 1866-1879.

141 Kirtane AR, Kalscheuer SM, Panyam J. Exploiting nanotechnology to overcome tumor drug resistance: Challenges and opportunities. Adv Drug Deliv Rev 2013; 65: 1731-1747.

142 Gorrini C, Harris IS, Mak TW. Modulation of oxidative stress as an anticancer strategy. Nat Rev Drug Discov 2013; 12: 931-947.

143 Trachootham D, Alexandre J, Huang P. Targeting cancer cells by ROS-mediated mechanisms: a radical therapeutic approach? Nat Rev Drug Discov 2009; 8: 579-591.

144 Noh J, Kwon B, Han E, Park M, Yang W, Cho W et al. Amplification of oxidative stress by a dual stimuli-responsive hybrid drug enhances cancer cell death. Nat Commun 2015; 6: 6907.

145 Abolhoda A, Wilson AE, Ross H, Danenberg PV, Burt M, Scotto KW. Rapid activation of MDR1 gene expression in human metastatic sarcoma after in vivo exposure to doxorubicin. Clin Cancer Res 1999; 5: 3352-3356.

146 Mai Y, Yu JJ, Bartholdy B, Xu-Monette ZY, Knapp EE, Yuan F et al. An oxidative stress-based mechanism of doxorubicin cytotoxicity suggests new therapeutic strategies in ABC-DLBCL. Blood 2016; 128: 2797-2807.

147 Kalinowski DS, Stefani C, Toyokuni S, Ganz T, Anderson GJ, Subramaniam NV et al. Redox cycling metals: Pedaling their roles in metabolism and their use in the development of novel therapeutics. Biochim Biophys Acta 2016; 1863: 727-748.

148 Valentine JS, Doucette PA, Zittin Potter S. Copper-zinc superoxide dismutase and amyotrophic lateral sclerosis. Annu Rev Biochem 2005; 74: 563-593.

149 Prasad AS, Bao B, Beck FW, Kucuk O, Sarkar FH. Antioxidant effect of zinc in humans. Free Radic Biol Med 2004; 37: 1182-1190.

150 Gyulkhandanyan AV, Lu H, Lee SC, Bhattacharjee A, Wijesekara N, Fox JE et al. Investigation of transport mechanisms and regulation of intracellular $\mathrm{Zn2}+$ in pancreatic alpha-cells. J Biol Chem 2008; 283: 10184-10197.

151 Ninsontia C, Phiboonchaiyanan PP, Chanvorachote P. Zinc induces epithelial to mesenchymal transition in human lung cancer $\mathrm{H} 460$ cells via superoxide aniondependent mechanism. Cancer Cell Int 2016; 16: 48.

152 Taylor KM, Muraina I, Brethour D, Schmitt-Ulms G, Nimmanon T, Ziliotto S et al. Zinc transporter ZIP10 forms a heteromer with ZIP6 which regulates embryonic development and cell migration. Biochem J 2016; 473: 2531-2544.

153 Yamashita S, Miyagi C, Fukada T, Kagara N, Che YS, Hirano T. Zinc transporter LIVI controls epithelial-mesenchymal transition in zebrafish gastrula organizer Nature 2004; 429: 298-302.

154 Wedeen RP, Qian LF. Chromium-induced kidney disease. Environ Health Perspect 1991; 92: 71-74.

155 Gibb HJ, Lees PS, Pinsky PF, Rooney BC. Lung cancer among workers in chromium chemical production. Am J Ind Med 2000; 38: 115-126.

156 Takahashi Y, Kondo K, Ishikawa S, Uchihara H, Fujino H, Sawada N et al. Microscopic analysis of the chromium content in the chromium-induced malignant and premalignant bronchial lesions of the rat. Environ Res 2005; 99: 267-272.

157 Ding SZ, Yang YX, Li XL, Michelli-Rivera A, Han SY, Wang L et al. Epithelialmesenchymal transition during oncogenic transformation induced by hexavalent chromium involves reactive oxygen species-dependent mechanism in lung epithelial cells. Toxicol Appl Pharmacol 2013; 269: 61-71.

158 Li WJ, Yang CL, Chow KC, Kuo TW. Hexavalent chromium induces expression of mesenchymal and stem cell markers in renal epithelial cells. Mol Carcinog 2016; 55: 182-192.

159 Marin JJ, Lozano E, Perez MJ. Lack of mitochondrial DNA impairs chemical hypoxia-induced autophagy in liver tumor cells through ROS-AMPK-ULK1 signaling dysregulation independently of HIF-1alpha. Free Radic Biol Med 2016; 101: $71-84$

160 Jeong SH, Jeon YJ, Park SJ. Inhibitory effects of dieckol on hypoxia-induced epithelial-mesenchymal transition of HT29 human colorectal cancer cells. Mol Med Rep 2016; 14: 5148-5154.

161 Li S, Zhang J, Yang H, Wu C, Dang X, Liu Y. Copper depletion inhibits $\mathrm{CoCl} 2$-induced aggressive phenotype of MCF-7 cells via downregulation of HIF-1 and inhibition of Snail/Twist-mediated epithelial-mesenchymal transition. Sci Rep 2015; 5: 12410. 
162 Lu H, Shi X, Costa M, Huang C. Carcinogenic effect of nickel compounds. Mol Cell Biochem 2005; 279: 45-67.

163 Wu CH, Tang SC, Wang PH, Lee H, Ko JL. Nickel-induced epithelial-mesenchymal transition by reactive oxygen species generation and E-cadherin promoter hypermethylation. J Biol Chem 2012; 287: 25292-25302.

164 Kang J, Zhang Y, Chen J, Chen H, Lin C, Wang Q et al. Nickel-induced histone hypoacetylation: the role of reactive oxygen species. Toxicol Sci 2003; 74: 279-286.

165 Dahdouh F, Raane M, Thevenod F, Lee WK. Nickel-induced cell death and survival pathways in cultured renal proximal tubule cells: roles of reactive oxygen species, ceramide and ABCB1. Arch Toxicol 2014; 88: 881-892.

166 Watson J. Oxidants, antioxidants and the current incurability of metastatic cancers. Open Biol 2013; 3: 120144.

167 Millea PJ. N-acetylcysteine: multiple clinical applications. Am Fam Physician 2009; 80: $265-269$.

168 Qin Y, Zhao D, Zhou HG, Wang XH, Zhong WL, Chen S et al. Apigenin inhibits NFkappaB and snail signaling, EMT and metastasis in human hepatocellular carcinoma. Oncotarget 2016; 7: 41421-41431.

169 Cao J, Wang H, Chen F, Fang J, Xu A, Xi W et al. Galangin inhibits cell invasion by suppressing the epithelial-mesenchymal transition and inducing apoptosis in renal cell carcinoma. Mol Med Rep 2016; 13: 4238-4244.

170 Meng X, Wu J, Pan C, Wang H, Ying X, Zhou Y et al. Genetic and epigenetic down-regulation of microRNA-212 promotes colorectal tumor metastasis via dysregulation of MnSOD. Gastroenterology 2013; 145: 426-436. e421-426.

171 Niu W, Zhang M, Chen H, Wang C, Shi N, Jing X et al. Peroxiredoxin 1 promotes invasion and migration by regulating epithelial-to-mesenchymal transition during oral carcinogenesis. Oncotarget 2016; 7: 47042-47051.

172 Catalano V, Turdo A, Di Franco S, Dieli F, Todaro M, Stassi G. Tumor and its microenvironment: a synergistic interplay. Semin Cancer Biol 2013; 23: 522-532.

173 Yoshida GJ, Saya H. Therapeutic strategies targeting cancer stem cells. Cancer Sci 2016; 107: 5-11.
174 Nagano O, Okazaki S, Saya H. Redox regulation in stem-like cancer cells by CD44 variant isoforms. Oncogene 2013; 32: 5191-5198.

175 Grote K, Flach I, Luchtefeld M, Akin E, Holland SM, Drexler $\mathrm{H}$ et al. Mechanical stretch enhances mRNA expression and proenzyme release of matrix metalloproteinase-2 (MMP-2) via $\mathrm{NAD}(\mathrm{P}) \mathrm{H}$ oxidase-derived reactive oxygen species. Circ Res 2003; 92: e80-e86.

176 Lim SO, Gu JM, Kim MS, Kim HS, Park YN, Park CK et al. Epigenetic changes induced by reactive oxygen species in hepatocellular carcinoma: methylation of the E-cadherin promoter. Gastroenterology 2008; 135: 2128-2140, e2121-2128.

177 Kamarajugadda S, Stemboroski L, Cai Q, Simpson NE, Nayak S, Tan M et al. Glucose oxidation modulates anoikis and tumor metastasis. Mol Cell Biol 2012; 32: $1893-1907$.

178 Zhu P, Tong BM, Wang R, Chen JP, Foo S, Chong HC et al. Nox4-dependent ROS modulation by amino endoperoxides to induce apoptosis in cancer cells. Cell Death Dis 2013; 4: e552.

179 Celia-Terrassa T, Kang Y. Distinctive properties of metastasis-initiating cells. Genes Dev 2016; 30: 892-908.

180 Seguin L, Desgrosellier JS, Weis SM, Cheresh DA. Integrins and cancer: regulators of cancer stemness, metastasis, and drug resistance. Trends Cell Biol 2015; 25: 234-240.

(i) This work is licensed under a Creative Commons Attribution 4.0 International License. The images or other third party material in this article are included in the article's Creative Commons license, unless indicated otherwise in the credit line; if the material is not included under the Creative Commons license, users will need to obtain permission from the license holder to reproduce the material. To view a copy of this license, visit http://creativecommons.org/licenses/ by/4.0/

(c) The Author(s) 2017 